\title{
Noninvasive Respiratory Support for Postextubation Respiratory Failure
}

\author{
Robert M Kacmarek
}

\author{
Introduction \\ Types of Respiratory Support \\ NIV \\ CPAP \\ HFNC \\ NIV Postextubation in the ICU for ARF \\ NIV Postextubation After a Failed Spontaneous Breathing Trial \\ Passed an SBT but High Risk for Re-Intubation \\ NIV for Extubation Failure, Developing ARF \\ Postoperative Use of NIV \\ Summary of Postoperative Use of NIV \\ CPAP Postextubation After Surgery \\ CPAP Postextubation in Subjects After Cardiac Surgery \\ CPAP Postextubation in Abdominal and/or Thoracic Surgical Subjects \\ CPAP Postextubation, Vascular Surgery \\ CPAP After Bariatric Surgery \\ Summary of CPAP Postextubation After Surgery \\ HFNC Postextubation in Surgical Subjects \\ HFNC in Postextubation Cardiac Surgical Subjects \\ Summary of HFNC in Surgical Subjects \\ HFNC Postextubation in General ICU Populations \\ Summary of HFNC in Postextubation Subjects in General ICU \\ Summary
}

The rate of re-intubation after endotracheal extubation for all indications is estimated at $\sim 20 \%$. This high rate is related, in part, to the development of postoperative complications that leads to acute respiratory failure that requires re-intubation. In general, 5-10\% of all surgical patients develop postoperative respiratory failure, and, in patients who require abdominal surgery, up to $40 \%$ develop respiratory failure. The forms of respiratory support that have been shown to be most effective in managing postextubation respiratory failure and preventing re-intubation are noninvasive ventilation, CPAP, and high-flow nasal cannula. From an analysis of the data, it is clear that patients at high risk of re-intubation require CPAP, noninvasive ventilation, or high-flow nasal cannula after extubation to allow for a smooth transition to spontaneous breathing and to minimize the need for re-intubation. CPAP is most indicated in patients with atelectasis in which high levels of PEEP are needed, noninvasive ventilation is indicated in the patient unable to maintain an adequate minute ventilation without excessive work of breathing, and high-flow nasal cannula is indicated in the patient with severe hypoxemia that was not a result of marked atelectasis or severe ARDS. It is also clear that there are insufficient data to support the use of any of these therapies in patients at low risk for re-intubation or the development of postoperative pulmonary complications. Key words: CPAP; noninvasive ventilation; high-flow nasal cannula; re-intubation; acute respiratory failure; postoperative pulmonary complications. [Respir Care 2019;64(6):658-678. (C) 2019 Daedalus Enterprises] 


\section{Introduction}

The rate of re-intubation after endotracheal extubation for all indications is estimated at $\sim 20 \% .^{1,2}$ This high rate is related, in part, to the development of postoperative complications that leads to acute respiratory failure (ARF) that requires re-intubation. ${ }^{3-5}$ Atelectasis, pneumonia, bronchospasm, and pulmonary embolism as well as a myriad of systemic problems can lead to respiratory failure. ${ }^{6-8} \mathrm{In}$ addition, nonsurgical subjects with comorbidities, COPD, heart disease, obesity (body mass index $>35 \mathrm{~kg} / \mathrm{m}^{2}$ ), age ( $>65$ years), multiple weaning failures, increased sputum production, and upper-airway obstruction also have an increased likelihood of developing postextubation respiratory failure that requires re-intubation..$^{9,10}$

In general, $5-10 \%$ of all surgical patients develop postoperative respiratory failure, and, in patients who require abdominal surgery, up to $40 \%$ develop respiratory failure. ${ }^{11,12}$ Particularly in patients undergoing abdominal surgery, postoperative respiratory muscle dysfunction is common. ${ }^{13}$ Thoracic, abdominal, and diaphragmatic muscles can be compromised as well as the phrenic nerve being dysfunctional. ${ }^{14}$ All of this increases the likelihood of development of postoperative ARF. The forms of postextubation respiratory support that have been shown to be most effective in managing postextubation respiratory failure and preventing re-intubation are noninvasive ventilation (NIV), CPAP, and high-flow nasal cannula (HFNC). This review focused on comparing and contrasting these forms of respiratory support in adults after extubation and in identifying the circumstances in which each form of therapy is most indicated.

\section{Types of Respiratory Support}

\section{NIV}

NIV results in the same physiologic effects as invasive ventilation. With a properly fitting oronasal mask, ventilation and oxygenation can be titrated to the patient's ven-

Dr Kacmarek is affiliated with Respiratory Care, Massachusetts General Hospital, Boston, Massachusetts.

Dr Kacmarek discloses relationships with Medtronic, Orange Medical, and Venner Medical.

Dr Kacmarek presented a version of this paper at the 57th RESPIRATORY CARE Journal Conference, Noninvasive Respiratory Support in Adults, held June 14-15, 2018, in St Petersburg, Florida.

Correspondence: Robert M Kacmarek PhD RRT FAARC, Respiratory Care, Warren 1225, 55 Fruit Street, Massachusetts General Hospital, Boston, MA 02114. E-mail: rkacmarek@partners.org.

DOI: $10.4187 /$ respcare.06671
Table 1. Benefits of High-Flow Nasal Cannula

\begin{tabular}{l}
\hline Benefit \\
\hline Precise, consistent, high concentration of oxygen \\
Upper airway dead space reduced by 33\% \\
Reduced work of breathing \\
Reduced minute ventilation \\
Low-level CPAP \\
Improved comfort vs NIV or CPAP \\
Improved tolerance vs NIV or CPAP \\
NIV = noninvasive ventilation \\
\hline
\end{tabular}

tilatory demand similar to that with invasive ventilation. However, NIV has to be applied by oronasal mask or a similar type of interface. As a result, the primary concern with NIV is patient in tolerance due to discomfort. ${ }^{15}$ Pressure ulcers, drying of oral and/or pharyngeal secretions, sinus and ear pain, eye irritation, and gastric distention are common adverse effects, whereas aspiration, pneumothorax, and hypotension are infrequent adverse effects. ${ }^{15}$

\section{CPAP}

CPAP is the application of PEEP to the patient who is spontaneously breathing and not on mechanical ventilation. As with invasive application of CPAP, a consistent level of PEEP can be applied in levels up to and exceeding $20 \mathrm{~cm} \mathrm{H}_{2} \mathrm{O}$. Analysis of recent data indicates that the neural respiratory drive and breathing effort assessed by electrical activity of the diaphragm is similar with nasal CPAP and HFNC. ${ }^{16}$ As with NIV, patient tolerance of mask application and discomfort are primary problems with CPAP. ${ }^{15}$ Adverse effects associated with CPAP are also the same as with NIV. ${ }^{15}$

\section{HFNC}

HFNC is the application of a high flow of oxygen though a specially designed cannula. The proposed benefits of HFNC are a precise, consistent, and high concentration of delivered oxygen; ${ }^{17,18}$ wash out of $\mathrm{CO}_{2}$ from the upper airway, which reduces dead space ventilation by $\sim 33 \%$ and results in reduced minute ventilation ${ }^{19-22}$ and work of breathing; ${ }^{23}$ and the establishment of a low level of CPAP (Table 1). ${ }^{24-27}$ However, the CPAP established is based on numerous variables, including gas flow, leak volume, fitting of the cannula into a patient's nares, and the size of the patient. ${ }^{21}$ Importantly, because HFNC is administered at approximate body temperature and saturated with water vapor, it is usually well tolerated by patients in all age groups. Most of the adverse effects observed with NIV and CPAP have not been reported with HFNC. Secretion is- 
sues as a result of inadequate humidification and pressure ulcers on the top of the ears as a result of the cannula straps and around the nares are the most common adverse effects. $^{21}$

\section{NIV Postextubation in the ICU for ARF}

A number of randomized controlled trials (RCTs) were performed to evaluate NIV postextubation in the ICU for ARF. In most of these studies, the majority of the subjects had a history of COPD (Table 2).

\section{NIV Postextubation After a Failed Spontaneous Breathing Trial}

The use of NIV as a support and transition mode to unsupported spontaneous breathing in patients with COPD for whom a spontaneous breathing trial (SBT) failed was evaluated in 5 RCTs. ${ }^{10,28-31}$ After $48 \mathrm{~h}$ of invasive ventilation and a failed SBT, Nava et $\mathrm{al}^{28}$ randomized subjects with COPD to either pressure support ventilation (PSV) or extubation to NIV. A total of 50 subjects were randomized, 25 to each group. At $60 \mathrm{~d}, 68 \%$ of the subjects in the PSV group were weaned, and $88 \%$ of the subjects who received NIV were weaned. The mean duration of mechanical ventilation was longer in the PSV group versus the NIV group $(P=.02), 16.6 \pm 11.8 \mathrm{~d}$ versus $10.2 \pm 6.8 \mathrm{~d}$. For patients receiving NIV, the probability of survival and weaning was higher $(P=0.002)$ and time in the ICU was shorter (mean $\pm \mathrm{SD}, 15.1 \pm 5.4 \mathrm{~d}$ versus $24.0 \pm 13.7 \mathrm{~d}$ for patients who received invasive ventilation; $P=0.005$ ). At $60 \mathrm{~d}, 92 \%$ of the subjects in the NIV group survived and $72 \%$ of the subjects in the PSV group survived, $P=.009$. Girault et al ${ }^{29}$ studied 33 subjects with COPD for whom an SBT also failed. As with Nava et al, ${ }^{28}$ the subjects were randomized to remain intubated while receiving PSV $(n=16)$ or to be extubated to NIV $(n=17)$. In the NIV group, 13 of 17 were weaned, and 12 of 16 in the PSV group were weaned, $P>.05$. The duration of invasive ventilation was shorter, as expected with NIV (mean \pm $\mathrm{SD}, 4.56 \pm 1.85 \mathrm{~d}$ versus $7.69 \pm 3.79 \mathrm{~d}, P=.004)$. NIV reduced the total duration of ventilatory support but increased the time devoted to weaning (mean $\pm \mathrm{SD}$, $3.46 \pm 1.42 \mathrm{~d}$ versus $11.54 \pm 5.24 \mathrm{~d}, P=<.001)$. At 3 months, the length of ICU and hospital stays were similar. No differences in mortality were reported.

The third study in this group, by Ferrer et al, ${ }^{10}$ had a slightly different protocol; the subjects had to fail SBTs on 3 consecutive days, and only $\sim 50 \%$ of the 43 subjects randomized had COPD. The NIV group versus the PSV group had fewer days of mechanical ventilation (mean \pm $\mathrm{SD}, 9.5 \pm 8.3 \mathrm{~d}$ versus $20.1 \pm 13.1 \mathrm{~d}, P=.003)$, fewer ICU days (mean $\pm \mathrm{SD}, 14.1 \pm 9.2 \mathrm{~d}$ versus $25.0 \pm 12.5 \mathrm{~d}$, $P=.002$ ), fewer hospital days (mean $\pm \mathrm{SD}, 27.8 \pm 14.6 \mathrm{~d}$ versus $40.8 \pm 21.4 \mathrm{~d}, P=.03$ ), and greater ICU survival (90\% versus $56 \%, P=.045$ ). Trevisan et al ${ }^{30}$ randomized subjects who required mechanical ventilation $>48 \mathrm{~h}$ and failing a T-piece trial to NIV $(n=28)$ or continued invasive ventilation $(n=37)$. In both groups, ventilation times to T-piece trial were the same, $7.3 \pm 4.1 \mathrm{~d}$. There were no differences in the re-intubation rate, length of stay (LOS) in the ICU, or mortality. However, the NIV group had a lower pneumonia rate and lower need for tracheotomy.

The final RCT in this group was a second study by Girault et al. ${ }^{31}$ They randomized 208 subjects with COPD in whom their first SBT failed to 3 groups: continued invasive ventilation $(n=69)$, extubation to oxygen therapy $(n=70)$, and extubation to NIV $(n=69)$. Re-intubation rates did not differ with $30 \%$ of the subjects with invasive ventilation, $37 \%$ subjects of oxygen therapy, and $32 \%$ of subjects on NIV $(P=.65)$. Weaning failure rates, including postextubation ARFs, were lower in the NIV group (54\% invasive ventilation, $71 \%$ oxygen therapy, and $33 \%$ NIV; $P<.001)$. Weaning time was longer in the NIV group than in the invasive ventilation group, 2.5 versus $1.5 \mathrm{~d}, P=.033)$.

Although taken as a group, there is clear support for extubating patients with COPD after a failed SBT and managing them with NIV, this has not become a widespread routine standard of care. There is that underlying fear that patients who failed an SBT will fail extubation and require re-intubation. Yes, we do extubate these patients to NIV but only under select circumstances. Specifically, we extubate a patient who is slated for tracheostomy when the clinical team considers them weanable but the patient continually fails SBTs, and any patient for whom analysis of all of the data indicates that the patient should be able to wean from ventilatory support but keeps failing SBTs.

\section{Passed an SBT but High Risk for Re-Intubation}

NIV has proven to be the most effective postextubation modality in patients in the ICU who passed an SBT but are considered high risk for re-intubation. High risk has been defined as a history of COPD or congestive heart failure, multiple attempts at weaning before SBT success, APACHE (Acute Physiology and Chronic Health Evaluation) II $>12$ on the day of extubation, upper-airway obstruction, $>65$ years old, ineffective cough, or excessive airway secretions. ${ }^{32-35}$ Four RCTs address this issue. Nava et al ${ }^{32}$ randomized 97 subjects who required $>48 \mathrm{~h}$ of mechanical ventilation who passed an SBT and demonstrated one of the factors associated with high risk of extubation failure to NIV or to standard oxygen therapy after extubation. NIV was provided at least $8 \mathrm{~h}$ per day for $48 \mathrm{~h}$. The subjects who received NIV had a lower re-intubation rate (4 versus $12, P=.03$ ). However, mortality (12\% versus 


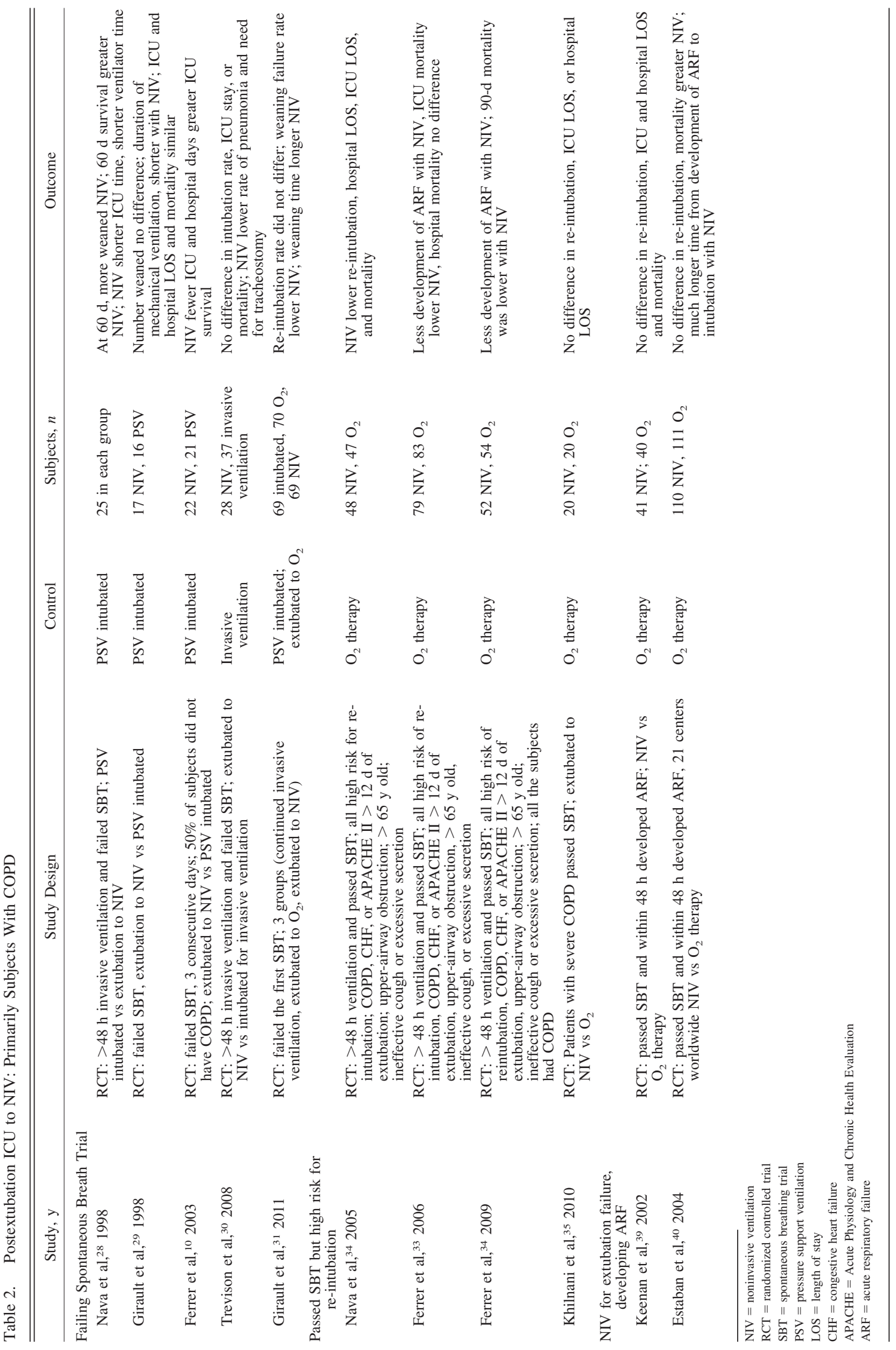


$18 \%$ ), ICU LOS (mean \pm SD, $8.9 \pm 5.7 \mathrm{~d}$ versus $11.6 \pm 14.9 \mathrm{~d}$ ), and hospital LOS (mean \pm SD, $23.3 \pm 16.4 \mathrm{~d}$ versus $25.5 \pm 21.4 \mathrm{~d}$ ) were not significantly different between the NIV and oxygen therapy groups, respectively.

Similar data were obtained by Ferrer et al. ${ }^{33}$ The investigators randomized 162 subjects at high risk to NIV or standard oxygen therapy. ARF developed in 13 of 79 subjects in the NIV group and in 27 of 83 subjects in the oxygen therapy group, $P=.03 .{ }^{33} \mathrm{NIV}$ was used as rescue in 19 control subjects, 9 of whom avoided intubation, and in 4 subjects on NIV, all avoided intubation. ${ }^{33}$ ICU mortality in the subjects with hypoxemic respiratory failure was lower in the NIV group $(P=.035)$; however, hospital mortality was unchanged. ${ }^{33}$

Ferrer et $\mathrm{al}^{34}$ performed a second RCT in this area. They randomized 106 subjects with chronic respiratory failure who passed an SBT and had one of the risk factors outlined above. Again, the development of ARF was the study end point. In the NIV group, 8 of 54 subjects developed $\mathrm{ARF}$, and 25 of 52 subjects in the oxygen therapy group developed ARF $(P<.001){ }^{34}$ The $90-d$ mortality was lower in the NIV group than in the oxygen therapy group, $P<.01 .^{34}$ Finally, Khilnani et al ${ }^{35}$ randomized a group of 40 subjects with severe COPD who were extubated after meeting weaning and extubation criteria to standard oxygen therapy or NIV (20 each group). They observed no differences in the re-intubation rate (NIV group, 15\%; oxygen therapy group, 25\%), ICU LOS after extubation (NIV group, $2.05 \pm 2.15 \mathrm{~d}$; oxygen therapy group, $1.55 \pm 0.82 \mathrm{~d}$ ) or hospital LOS (NIV group, $16.10 \pm 6.29 \mathrm{~d}$; oxygen therapy group, $18.25 \pm 7.91 \mathrm{~d}) .{ }^{35}$

Although the results are mixed, these studies establish the need to use NIV on patients at risk who were extubated after successful completion of an SBT. This should be the standard of care in our ICUs. The use of NIV postextubation in patients at high risk is recommended in the recent guidelines on liberation from mechanical ventilation from the American Thoracic Society and the American College of Chest Physicians. ${ }^{36}$ Patients at risk clearly have a greater probability of re-intubation than those not presenting with these risk factors, and it has been clearly established that patients who are re-intubated have a higher mortality. ${ }^{37,38}$

\section{NIV for Extubation Failure, Developing ARF}

This group of studies addressed a mixed group of subjects at high and low risk who passed an SBT but within 48 hours developed ARF postextubation. Keenan et $\mathrm{al}^{39}$ randomized 81 subjects who developed ARF (defined as a breathing frequency of $>30$ breaths/min, as an increase in breathing frequency of $>50 \%$, or as use of accessory muscles of respiration or abdominal paradox) to NIV or to standard oxygen therapy. The subjects eventually developed hypercarbic or hypoxemic ARF. The rate of re-intu- bation was the same between the groups (72\% versus $69 \%$ ), as was the hospital mortality ( $31 \%$ for both groups). In addition, no differences were found in the duration of mechanical ventilation or ICU or hospital LOS. ${ }^{39}$

Esteban et $\mathrm{al}^{40}$ performed a multi center ( 21 centers) worldwide study of 221 subjects who were randomized within $48 \mathrm{~h}$ after extubation if they met the following criteria: respiratory acidosis $\left(\mathrm{pH}<7.35\right.$ and $\mathrm{Pa}_{\mathrm{CO}_{2}}>45 \mathrm{~mm}$ $\mathrm{Hg}$ ), clinical signs suggestive of respiratory muscle fatigue or increased respiratory effort, a breathing frequency $>25$ breaths/min for 2 consecutive hours, and hypoxemia $\left(\mathrm{S}_{\mathrm{pO}_{2}}<90 \%\right.$ or $\mathrm{P}_{\mathrm{aO}_{2}}<80 \mathrm{~mm} \mathrm{Hg}$, with an $\left.\mathrm{F}_{\mathrm{IO}_{2}}>0.50\right)$. The re-intubation rate was the same in each group, $48 \%$; however, the ICU mortality was higher in the NIV group $(25 \%)$ than in the standard of care group $(14 \%)(P=.048) .{ }^{40}$ An explanation for this higher mortality in the NIV group may be because the time from development of respiratory failure to intubation was longer in the NIV group (12 h) compared with the standard of care group $(2.5 \mathrm{~h})(P=.02)$. It was assumed that subjects on NIV, although gas exchange was good, were working excessively to breathe during the 12-h period. ${ }^{40}$ Thus, potentially developing subject-induced lung injury by the excessive transpulmonary pressure that developed. ${ }^{41,42}$

Recent data from Yoshida et al ${ }^{43,44}$ clearly indicate that excessive effort and work of breathing during ventilatory support can induce localized overdistention and lung injury. It is for this reason that it has been highly recommended that, when NIV is applied for hypoxemic ARF, the assessment of the patient's response should occur frequently, and if the patient's clinical status does not improve within the first $1-2 \mathrm{~h}$, he or she should be intubated. ${ }^{45}$ That is, even if gas exchange is normalized but the patient's clinical presentation still indicates severe respiratory distress (rapid breathing frequency, small tidal volume, use of accessory muscles of ventilation, tachycardia, and hypertension), the patient should be intubated. ${ }^{45}$ Thus, the use of therapeutic NIV in postextubation respiratory failure must be questioned. It may be most beneficial for patients to be re-intubated if they develop respiratory failure. If NIV is attempted, then a very low threshold for failure should be established and intubation should not be delayed.

\section{Postoperative Use of NIV}

A number of RCTs address the use of NIV postextubation after surgical procedures (Table 3). ${ }^{46-54}$ NIV use after lung resection was studied by 3 groups. ${ }^{46,49,52}$ Aguiló et al ${ }^{46}$ randomized subjects to receive NIV $(n=10)$ versus oxygen therapy $(n=9)$ after surgery for $1 \mathrm{~h}$. The NIV group demonstrated an increase in $\mathrm{P}_{\mathrm{aO}_{2}}$, from $68.0 \pm 2.7 \mathrm{~mm} \mathrm{Hg}$ to $76.7 \pm 3.0 \mathrm{~mm} \mathrm{Hg}, P<.05$; the control group showed no change in $\mathrm{P}_{\mathrm{aO}}{ }_{2}{ }^{46}$ No other differences were noted. 


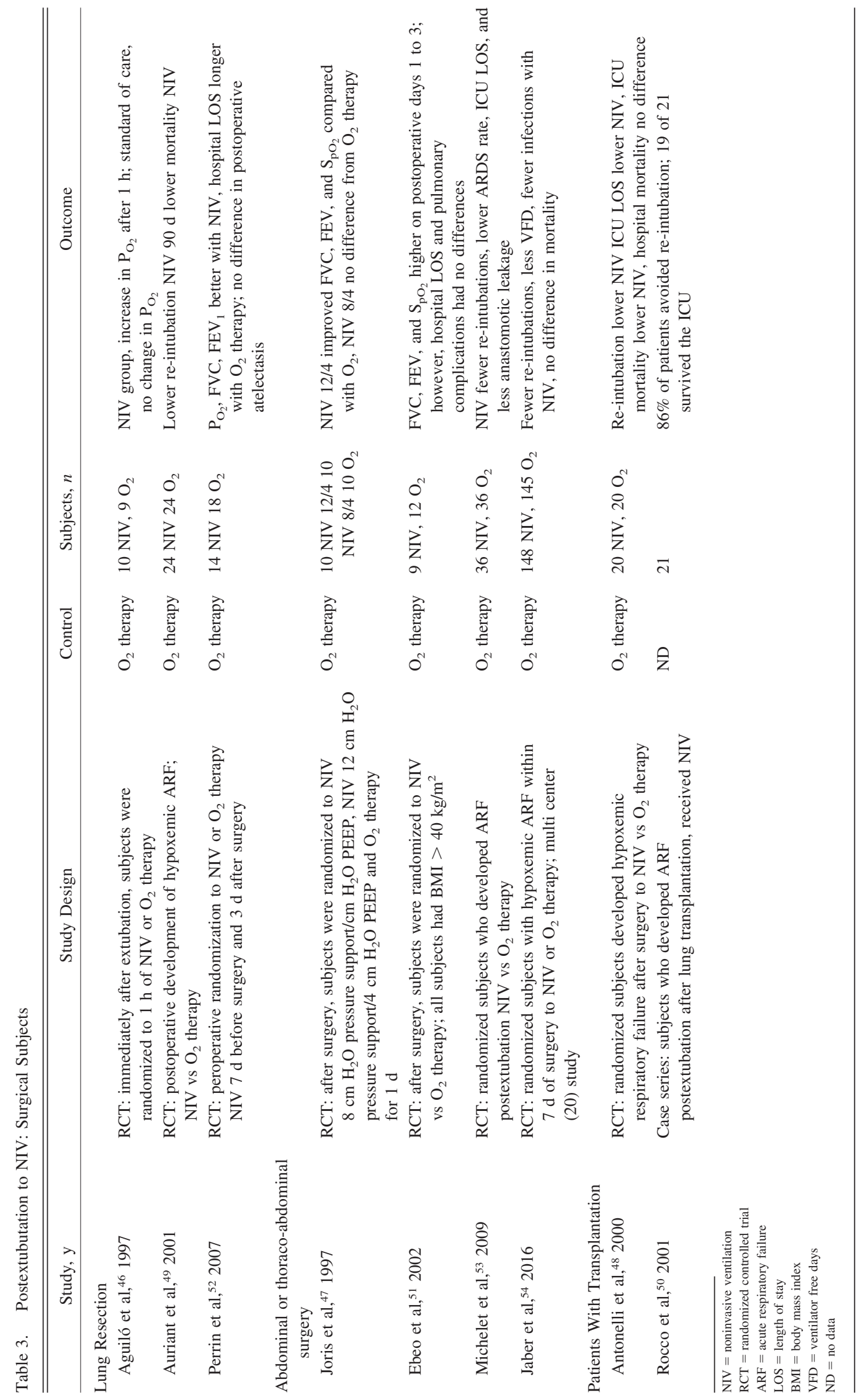


Auriant et $\mathrm{al}^{49}$ performed an RCT of subjects with postoperative lung resection who developed acute hypoxemic respiratory failure. The subjects were randomized to NIV or oxygen therapy. In the NIV group, 5 of 24 subjects required intubation versus 12 of 24 in the standard of care group, $P=.035 .{ }^{49}$ Mortality at $120 \mathrm{~d}$ was 9 subjects in the standard care group versus 3 in the NIV group $P=.045 .{ }^{49}$ All other outcomes were similar between the groups. Perrin et al ${ }^{52}$ compared NIV $(n=14)$ with standard of care $(n=18)$ before and after surgery in subjects who received elective lobectomy for lung cancer. The subjects were enrolled if their $\mathrm{FEV}_{1}$ was $<70 \%$ before surgery. ${ }^{52}$ The subjects in the NIV group received NIV $7 \mathrm{~d}$ before surgery at home and $3 \mathrm{~d}$ after surgery; the control group received no preoperative therapy, only postextubation oxygen therapy. ${ }^{52}$ Two hours after surgery and up until the third day postoperative $\mathrm{P}_{\mathrm{aO}}, \mathrm{FVC}$, and $\mathrm{FEV}_{1}$ were significantly better in the NIV group; hospital LOS was longer in the control group, $P=.04$, and the incidence of postoperative atelectasis was $14.2 \%$ in the NIV group versus $38.9 \%$ in the control group, $P=.15 .52$

The largest group of subjects studied were those who required abdominal or thoraco-abdominal surgery. ${ }_{47,51,53,54}$ Joris et $\mathrm{al}^{47}$ compared the use of NIV at $8 \mathrm{~cm} \mathrm{H}_{2} \mathrm{O}$ of pressure support over $4 \mathrm{~cm} \mathrm{H}_{2} \mathrm{O}$ of $\operatorname{PEEP}(n=10)$ and $4 \mathrm{~cm} \mathrm{H}_{2} \mathrm{O}$ of pressure support over $4 \mathrm{~cm} \mathrm{H}_{2} \mathrm{O}$ of PEEP $(n=10)$ to oxygen therapy $(n=10)$ in subjects after gastroplasty. The bi-level positive airway pressure at 12 $\mathrm{cm} \mathrm{H}_{2} \mathrm{O}$ Pressure support $4 \mathrm{~cm} \mathrm{H}_{2} \mathrm{O}$ PEEP significantly improved $\mathrm{FVC}, \mathrm{FEV}_{1}$, and $\mathrm{S}_{\mathrm{pO}_{2}}$ on postoperative day 1 compared with oxygen therapy; bi-level positive airway pressure at $8 \mathrm{~cm} \mathrm{H}_{2} \mathrm{O}$ pressure support $4 \mathrm{~cm} \mathrm{H}_{2} \mathrm{O}$ PEEP had no significant effect on any measured variable. ${ }^{47}$ No outcome data were presented. After gastric surgery for subjects with obesity (body mass index $>40 \mathrm{~kg} / \mathrm{m}^{2}$ ), Ebeo et $\mathrm{al}^{51}$ randomized subjects to bi-level positive airway pressure $(n=9)$ for the first $24 \mathrm{~h}$ or to oxygen therapy $(n=12)$. FVC, $\mathrm{FEV}_{1}$, and $\mathrm{S}_{\mathrm{pO}_{2}}$ were significantly higher in the bi-level positive airway pressure group over postoperative days 1 to 3 ; however, hospital days and postoperative pulmonary complication were similar between the groups. ${ }^{51}$

Michelet et al ${ }^{53}$ performed a matched case-control study of subjects after esophagectomy who developed ARF. NIV was applied to 36 subjects, and oxygen therapy was used in 36 subjects. The NIV group had fewer re-intubations ( 9 versus $23, P=.008)$, a lower frequency of ARDS (8 versus $19, P=.02)$, ICU LOS (14[13] d versus 22[18] d, $P=.01)$, and anastomotic leakage was less in the subjects who received NIV (2 versus $10, P=.03$ ). ${ }^{53}$ Most recently, Jaber et al, ${ }^{54}$ in a multi-center RCT ( 20 centers), randomized subjects with acute hypoxemic respiratory failure after abdominal surgery to NIV $(n=148)$ or standard oxygen therapy $(n=145)$. Hypoxemic ARF was defined as
$\mathrm{P}_{\mathrm{aO}_{2}}<60 \mathrm{~mm} \mathrm{Hg}$ or $\mathrm{S}_{\mathrm{pO}_{2}}<90 \%$ when breathing room air or $\mathrm{P}_{\mathrm{aO}_{2}}<80 \mathrm{~mm} \mathrm{Hg}$ when breathing $15 \mathrm{~L} / \mathrm{min}$ of oxygen plus either a frequency of $>30$ breaths/min or clinical signs of "intense" respiratory muscle work and/or increased work of breathing within $7 \mathrm{~d}$ of the surgical procedure..$^{54}$ Re-intubation occurred in $33.1 \%$ of the NIV group versus $45.5 \%$ of the subjects in the $\mathrm{O}_{2}$ therapy group, $P=.03 .{ }^{54}$ NIV resulted in more intensive ventilator-free days (23.2 versus $25.4 \mathrm{~d}, P=.04)$. Also, fewer subjects in the NIV group developed health-care-related infections (31.4\% versus $49.2 \%, P=.003)$; however, there were no significant differences in 90 -d mortality ( $14.9 \%$ in the NIV group versus $21.5 \%$ in the $\mathrm{O}_{2}$ group, $P=.15$ ) and gas exchange. ${ }^{54}$

There are 2 trials that focused on subjects with transplantations. ${ }^{48,50}$ Antonelli et al, ${ }^{48}$ randomized subjects who developed acute hypoxemic respiratory failure after solidorgan transplantation to NIV $(n=20)$ or oxygen therapy $(n=20)$. A sustained improvement in $\mathrm{P}_{\mathrm{aO}_{2}} / \mathrm{F}_{\mathrm{IO}_{2}}$ was observed in 12 subjects in the NIV group versus 5 in the standard of care group, $P=.03 .48$ The re-intubation rate was lower in the NIV group (20\%) versus the standard of care group (70\%), $P=.002$; ICU LOS was greater in the standard of care group versus the NIV group $(9[4] \mathrm{d}$, versus $5.5[3] \mathrm{d}, P=.03$ ) and ICU mortality was lower in the NIV group (20\% versus 50\%, $P=.05$ ); however, hospital mortality did not differ. ${ }^{48}$ Rocco et al ${ }^{50}$ reported a similar result in subjects after lung transplantation. In a case series in which 21 subjects who developed ARF were managed with NIV, $86 \%$ of the subjects avoided re-intubation, and a total of 19 of 21 subjects survived the ICU. ${ }^{50}$

\section{Summary of Postoperative Use of NIV}

Although the data on the use of NIV in the postoperative setting are mixed, the majority of the studies demonstrate a positive impact of NIV on postoperative complication, the re-intubation rate, and ICU LOS. As a result, NIV is indicated for the management of the postoperative patient. This is especially true in patients after abdominal procedures in which the impact on respiratory function after surgery is greatest. The use of NIV in these settings is supported by recent systematic reviews ${ }^{15,55}$ and by the recent guidelines of the European Respiratory Society/ American Thoracic Society. ${ }^{56}$ Although these guidelines specifically recommend use of NIV in the setting of ARF after intubation; prophylactic use after extubation is not mentioned.

\section{CPAP Postextubation After Surgery}

The vast majority of the data on the use of CPAP postextubation is after surgery (Tables 4 and 5). There have been a number of RCTs that addressed the use of CPAP 


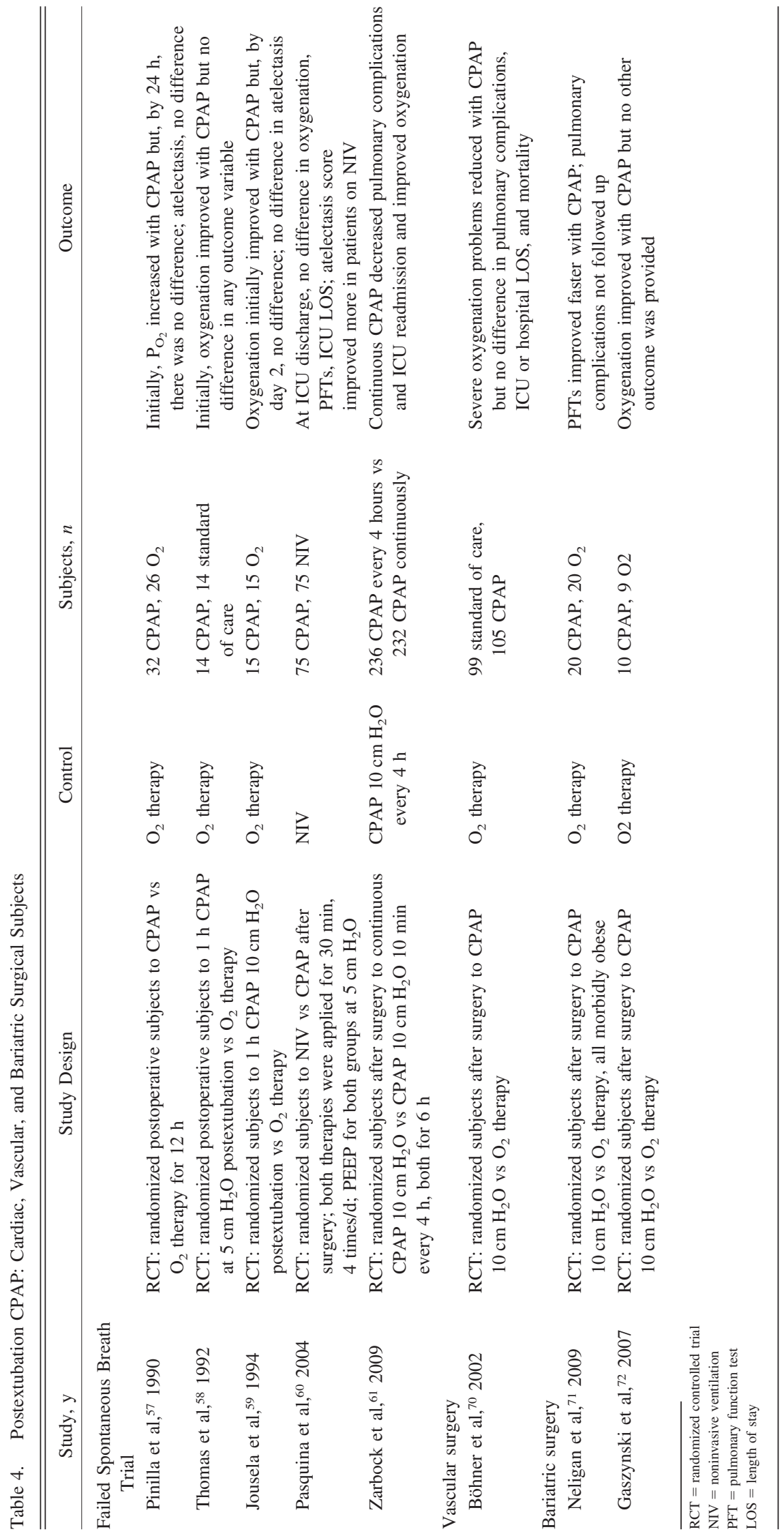




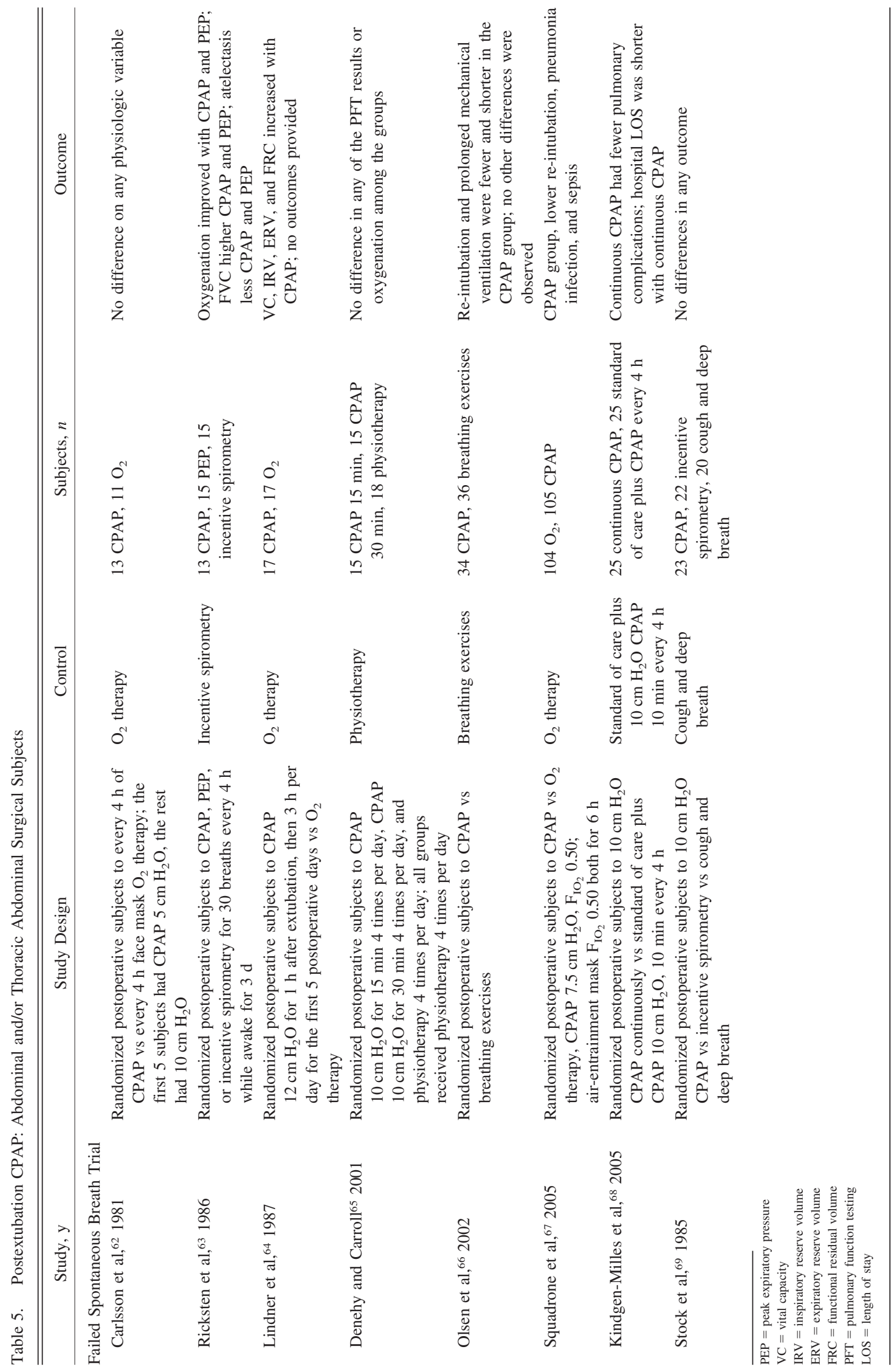


after cardiac surgery, ${ }^{57-61}$ abdominal and/or thoracic surgery, ${ }^{62-69}$ vascular surgery, ${ }^{70}$ and bariatric surgery. ${ }^{71,72}$

\section{CPAP Postextubation in Subjects After Cardiac Surgery}

Pinilla et al ${ }^{57}$ randomized subjects who had postoperative coronary artery bypass to receive CPAP $(n=32)$ versus standard of care $(n=26)$. All the subjects were ventilated with $5 \mathrm{~cm} \mathrm{H}_{2} \mathrm{O}$ PEEP for $\sim 18 \mathrm{~h}$, then $5 \mathrm{~cm} \mathrm{H}_{2} \mathrm{O}$ face mask CPAP or oxygen therapy for $12 \mathrm{~h}$ after extubation. ${ }^{57}$ Initially $\mathrm{P}_{\mathrm{aO}_{2}}$ was significantly increased in the CPAP group, but, by $24 \mathrm{~h}$ postextubation, there was no difference in $\mathrm{P}_{\mathrm{aO}}$; there also was no difference in the development of atelectasis..$^{57}$ Thomas et al ${ }^{58}$ and Jousela et al ${ }^{59}$ performed similar studies in subjects who were postoperative coronary artery bypass. Subjects in the study by Thomas et al ${ }^{58}$ were randomized to $1 \mathrm{~h}$ of $5 \mathrm{~cm} \mathrm{H}_{2} \mathrm{O}$ CPAP postextubation $(n=14)$ or to oxygen therapy $(n=14)$. Initially, the oxygenation status was better in the CPAP group, but there were no differences on any outcome variable. ${ }^{58}$

In the study by Jousela et al, ${ }^{59}$ the subjects were also randomized to CPAP $(n=15)$ or oxygen therapy $(n=15)$ after extubation, but CPAP was applied at $10 \mathrm{~cm} \mathrm{H}_{2} \mathrm{O}$. As with the studies by Pinilla et al ${ }^{57}$ and Thomas et al, ${ }^{58}$ in the study by Jousela et al, ${ }^{59}$ the CPAP group responded with improved oxygenation, but, by day 2 , this improvement was lost and there again was no difference in the development of atelectasis. Pasquina et $\mathrm{al}^{60}$ compared the benefit of NIV $(n=75)$ with CPAP $(n=75)$ in subjects who were postoperative coronary artery bypass. Both techniques were applied for $30 \mathrm{~min}, 4$ times per day. PEEP in both groups was $5 \mathrm{~cm} \mathrm{H}_{2} \mathrm{O}$, and NIV was adjusted to provide a tidal volume of $8-10 \mathrm{~mL} / \mathrm{kg}$. At ICU discharge, there were no differences in oxygenation, pulmonary function tests, or LOS; however, the atelectasis score improved in $60 \%$ of subjects in the NIV group versus $40 \%$ in the CPAP group $(P=.02){ }^{60}$

The most convincing study regarding the use of CPAP after coronary artery bypass was by Zarbock et al. ${ }^{61}$ They compared $10 \mathrm{~cm} \mathrm{H}_{2} \mathrm{O}$ CPAP given for 10 min every $4 \mathrm{~h}$ ( $n=236$ ) with continuous CPAP at $10 \mathrm{~cm} \mathrm{H}_{2} \mathrm{O}$ for $6 \mathrm{~h}$ $(n=232){ }^{61}$ The continuous CPAP group had improved oxygenation and fewer pulmonary complications (12/232 versus $25 / 236, P=.03$ ). The ICU readmission rate was also lower in the continuous CPAP group (7/232 versus 14/236 subjects, $P=.03){ }^{61}$

The analyses of these data have not had a widespread affect on the postoperative management of the patient with a coronary artery bypass. It is infrequent that these patients will receive prophylactic continuous CPAP. The application of CPAP is more likely in select postoperative patients who present with significant comorbidities or gas exchange problems than the widespread prophylactic application to all patients.

\section{CPAP Postextubation in Abdominal and/or Thoracic Surgical Subjects}

The data on the use of CPAP in subjects with postoperative abdominal and/or thoracic surgery is split (Table 5). Earlier studies showed negative results ${ }^{62,65,69}$ but morerecent studies demonstrate the beneficial effects of CPAP. ${ }^{63,64,66-68}$ Carlsson et al ${ }^{62}$ randomized subjects to CPAP $\left(5\right.$ or $\left.10 \mathrm{~cm} \mathrm{H}_{2} \mathrm{O}\right)$ for $4 \mathrm{~h}(n=13)$ versus oxygen therapy $(n=11)$. No differences of any type were observed between the two groups. Similar data were observed by Denehy and Carroll ${ }^{65}$ and Stock et al ${ }^{69}$ Denehy and Carroll 65 compared the effect of CPAP $10 \mathrm{~cm} \mathrm{H}_{2} \mathrm{O}$ given for $15 \mathrm{~min}(n=17)$ or $30 \mathrm{~min}(n=15) 4$ times per day for the first 3 postoperative days to physiotherapy twice daily $(n=18)$. All 3 groups received physiotherapy daily. The use of CPAP did not affect any clinical or physiologic variable. Stock et al ${ }^{69}$ compared CPAP with incentive spirometry and with cough and deep breathing but observed no differences among the 3 groups.

The first study to our knowledge to find benefit of CPAP in subjects with postoperative abdominal surgery was the study by Ricksten et al ${ }^{63}$ They compared the effects of $10-15 \mathrm{~cm} \mathrm{H}_{2} \mathrm{O}$ CPAP $(n=12)$ with that of positive expiratory pressure therapy $(n=15)$ and incentive spirometry $(n=15)$. CPAP, positive expiratory pressure therapy, and incentive spirometry were administered for 30 breaths every hour while awake for $3 \mathrm{~d}$. CPAP and positive expiratory pressure therapy resulted in better oxygenation and a lower incidence of atelectasis than with the incentive spirometry group. Lindner et al ${ }^{64}$ also found CPAP $(n=17)$ superior to the standard of care $(n=17)$. They randomized subjects to $12 \mathrm{~cm} \mathrm{H}_{2} \mathrm{O}$ CPAP for $1 \mathrm{~h}$ after extubation and then $3 \mathrm{~h}$ a day for the first 5 postoperative days. Vital capacity, inspiratory reserve volume, expiratory reserve volume, and functional residual capacity were all significantly increased in the CPAP group. However, there were no differences in postoperative pulmonary complications.

Olsen et al ${ }^{66}$ randomized subjects to $5-10 \mathrm{~cm} \mathrm{H}_{2} \mathrm{O}$ CPAP $(n=34)$ versus breathing exercises by inspiratory resistance positive expiratory pressure therapy $(n=36)$. Reintubation and prolonged mechanical ventilation were higher in the inspiratory resistance positive expiratory pressure therapy group ( 7 of 36 ) versus CPAP ( 1 of 34 ), $P<.05 .66$ All other comparisons were not significantly different. The largest and most definitive trial was that performed by Squadrone et al. ${ }^{67}$ They randomized subjects to receive oxygen therapy $(n=104)$ versus $\operatorname{CPAP}(n=105)$. Oxygen therapy was administered via 50\% air-entrainment mask for $6 \mathrm{~h}$ and $\mathrm{CPAP}$ at $7.5 \mathrm{~cm} \mathrm{H}_{2} \mathrm{O}$ and $50 \%$ oxygen for $6 h .{ }^{67}$ After $6 \mathrm{~h}$, both groups were transitioned 
to a $30 \%$ air-entrainment mask for $1 \mathrm{~h}$ and their $\mathrm{P}_{\mathrm{aO}_{2}} / \mathrm{F}_{\mathrm{IO}_{2}}$ was evaluated. ${ }^{67}$ If the ratio was $<300 \mathrm{~mm} \mathrm{Hg}$, then the subjects were placed back on the study settings, but if the ratio was $>300 \mathrm{~mm} \mathrm{Hg}$, then treatment was stopped. ${ }^{67}$ If the subjects did not tolerate either arm of the study, then they were given a nasal cannula at $8-10 \mathrm{~L} / \mathrm{min}$. The CPAP group had a lower re-intubation rate (1\% versus $10 \%$, $P=.005)$, and a lower rate of pneumonia (2\% versus $10 \%, P=.02$ ), infection (3\% versus $10 \%, P=.03$ ), and sepsis $(2 \%$ versus $9 \%, P=.03) .{ }^{67}$

Kindgen-Milles et al ${ }^{68}$ randomized subjects to $10 \mathrm{~cm} \mathrm{H}_{2} \mathrm{O}$ continuous CPAP $(n=25)$ versus standard of care plus $10 \mathrm{~cm} \mathrm{H}_{2} \mathrm{O}$ CPAP for 10 min every $4 \mathrm{~h}(n=25)$. The use of continuous CPAP resulted in fewer pulmonary complications ( 7 of 25 versus 24 of $25, P=.019$ ) and shorter hospital $\operatorname{LOS}(22 \pm 2 \mathrm{~d}$ vs $34 \pm 5 \mathrm{~d}, P=.048)$, whereas ICU LOS trended shorter $(8 \pm 1 \mathrm{~d}$ versus $12 \pm 2 \mathrm{~d})$ but not significantly. ${ }^{68}$

The studies by Squadrone et $\mathrm{al}^{67}$ and KindgenMilles et al $^{68}$ provide strong support for the use of CPAP postextubation in patients after abdominal surgery, similar to the beneficial effects of NIV in this population. The use of CPAP in these patients is supported by recent systematic reviews ${ }^{15,55}$ and guidelines. ${ }^{56}$ However, again, widespread prophylactic application of CPAP postextubation in all patients with abdominal surgery is lacking. As with NIV application, CPAP seems to be reserved for patients who present with a high risk for re-intubation and ARF.

\section{CPAP Postextubation, Vascular Surgery}

Only one study, by Bohner et al, ${ }^{70}$ was identified. They studied the effects of CPAP $10 \mathrm{~cm} \mathrm{H}_{2} \mathrm{O}(n=99)$ versus oxygen therapy $(n=105)$ in subjects who required midline laparotomy for vascular surgery. Severe oxygenation problems were reduced with CPAP (95 versus 17 subjects, $P=.01)$, but there were no differences in pulmonary complications, ICU or hospital LOS, or mortality.

\section{CPAP After Bariatric Surgery}

Neligan et $\mathrm{al}^{71}$ and Gaszynski et $\mathrm{al}^{72}$ studied the use of CPAP after bariatric surgery. Neligan et al $^{71}$ randomized subjects to CPAP $(n=20)$ provided by the Boussignac valve at $9.4 \mathrm{~cm} \mathrm{H}_{2} \mathrm{O}$ or to oxygen therapy $(n=20)$. Pulmonary function improved significantly faster in the CPAP group than in the oxygen therapy group. However they did not follow up postoperative pulmonary complications. Gaszynski et al ${ }^{72}$ randomized 19 subjects who were morbidly obese to CPAP $(n=10)$ or to standard of care $(n=9)$, with CPAP again provided by the Boussignac valve at $9.4 \mathrm{~cm} \mathrm{H}_{2} \mathrm{O}$. The subjects who received CPAP had a higher $\mathrm{P}_{\mathrm{aO}_{2}}$ at $30 \mathrm{~min}, 4 \mathrm{~h}$, and $8 \mathrm{~h}$ postextubation than the standard of care group (mean \pm SD of all time points $81.0 \pm 16.0 \mathrm{~mm} \mathrm{Hg}$ versus $65 \pm 4.9 \mathrm{~mm} \mathrm{Hg}$, $P<.05)$. No other outcomes were indicated.

These 2 studies were mostly negative because of the level of CPAP applied. Patients who are morbidly obese require a high level of $\mathrm{PEEP}$ to stabilize the lung, and the $9.4 \mathrm{~cm} \mathrm{H}_{2} \mathrm{O}$ CPAP used in these studies was most likely inadequate. ${ }^{73,74}$ Postoperative patients who are morbidly obese are the most in need of noninvasive ventilatory support postextubation. The use of CPAP in the $10-15 \mathrm{~cm} \mathrm{H}_{2} \mathrm{O}$ range for management of sleep apnea should be applied to all of these patients immediately postextubation and slowly decreased over the next 24-48 h. But again, widespread application of prophylactic CPAP in this group is lacking.

\section{Summary of CPAP Postextubation After Surgery}

In 2010, Chiumello et at $^{3}$ identified 29 clinical trials associated with the use of NIV or CPAP in the surgical postextubation setting. In 15 of 22 prophylactic studies and 4 of 7 therapeutic studies in which noninvasive ventilatory support was provided, gas exchange improved. Re-intubation was reduced in 11 of the total 29 studies, but other outcomes were improved in only 1 study. In spite of this limited benefit, they recommend the use of NIV or CPAP postextubation in surgical patients, with similar recommendations made by Jaber et al ${ }^{55}$ in 2014. Most recently, in 2017, the European Respiratory Society/American Thoracic Society guidelines ${ }^{56}$ recommended the use of NIV or CPAP for postoperative respiratory failure. Clearly, the use of NIV and/or CPAP in postoperative respiratory failure is indicated, but the prophylactic application of NIV and/or CPAP should be considered primarily in patients at high risk of re-intubation. The definition of high risk has varied in the literature, but most clinicians would agree that patients with a history of COPD or congestive heart failure, body mass index $>40 \mathrm{~kg} / \mathrm{m}^{2}$, age $>65$ y, multiple SBT failures, excessive secretions, and upper-airway obstruction meet the definition..$^{9,10}$

\section{HFNC Postextubation in Surgical Subjects}

A number of clinical trials that addressed the use of HFNC postextubation in surgical subjects have been performed (Tables 6 and 7). General surgical populations, ${ }^{73,74}$ renal transplantation recipients, ${ }^{75}$ major abdominal surgery subjects, ${ }^{76}$ and cardiac surgical subjects ${ }^{77-79}$ were studied.

Dhillon et al ${ }^{75}$ retrospectively reviewed surgical cases with ARF postextubation from August 2015 to February 2016. They identified 46 subjects managed with HFNC, and 138 well-matched subjects managed with cool mist nasal cannula. Before extubation, the subjects with HFNC had a longer length of mechanical ventilation (7.1 versus 3.4 mean $\mathrm{d}, P<.01)$ and ICU stay (7.8 versus 4.1 mean $\mathrm{d}, P<.01) .{ }^{75}$ The raw re-intubation rates were similar between the 2 groups; 


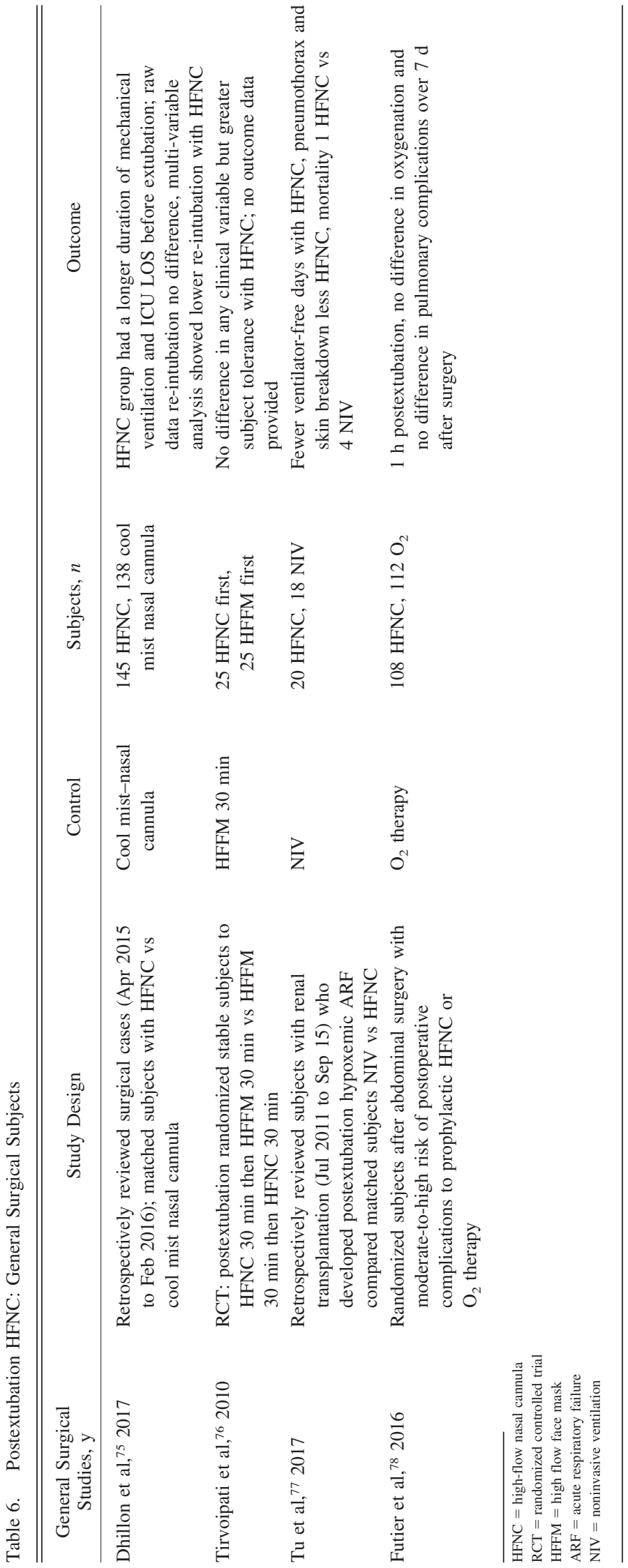




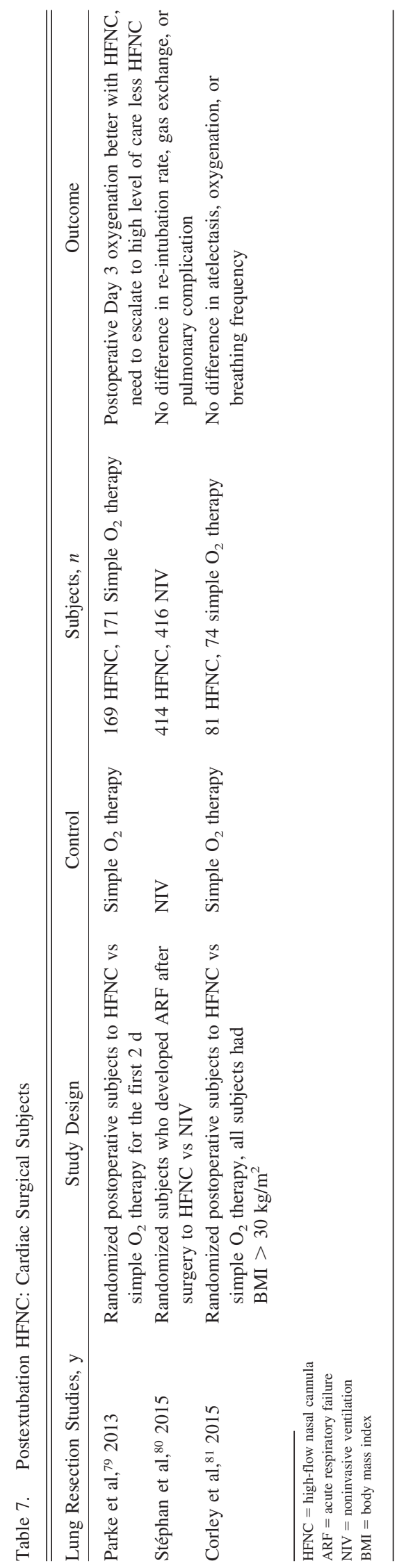

however, multivariate analysis indicated a lower intubation rate with $\mathrm{HFNC}(P=.02)$. Tiruvoipati et al $^{76}$ randomly compared 2 protocols in a general surgical population: highflow face mask for $30 \mathrm{~min}$, followed by HFNC for $30 \mathrm{~min}$ $(n=25)$; and HFNC for $30 \mathrm{~min}$, followed by high-flow face mask for 30 min $(n=25)$, each applied in stable subjects after extubation. ${ }^{76}$ There were no significant differences in gas exchange, respiratory, or cardiovascular variables; however, there was greater subject tolerance with $\operatorname{HFNC}(P=.01)$ and a trend toward better comfort $(P=.09)$, although no outcome variables were evaluated. ${ }^{76}$

$\mathrm{Tu}$ et $\mathrm{al}^{77}$ retrospectively reviewed data from subjects with renal transplantation from July 2011 to September 2015, who developed acute hypoxemic respiratory failure postextubation. A total of 38 subjects were identified, including 20 who received HFNC and 18 who received NIV. One subject in the HFNC group versus 4 in the NIV group died $(P=.008)$. Ventilator-free days at hospital day 28 were $26 \pm 3$ HFNC group versus $21 \pm 3$ NIV group $(P<.001)$. The incidence of pneumothorax ( $0 \%$ versus $22 \%, P=.042)$ and skin breakdown (0\% versus $22.2 \%, P=.042)$ were lower in the HFNC group. Futier et $\mathrm{al}^{78}$ randomized subjects with major abdominal surgery and with a moderate-to-high risk of postoperative pulmonary complications to prophylactic application of HFNC $(n=108)$ versus oxygen therapy $(n=112)$. The primary outcome was hypoxemia at 1 postextubation and after treatment discontinuation. At $1 \mathrm{~h}$ postextubation, $23 \mathrm{sub}$ jects with HFNC versus 27 subjects with oxygen therapy developed hypoxemia, and 29 subjects with HFNC versus 34 subjects with oxygen therapy developed hypoxemia after discontinuation of therapy $(P=.58)$. Pulmonary complications over the $7 \mathrm{~d}$ postextubation did not differ between the groups nor did any other secondary outcomes.

\section{HFNC in Postextubation Cardiac Surgical Subjects}

The first RCT that evaluated the use of HFNC in subjects with cardiac surgery was performed by Parke et al. ${ }^{79}$ They randomized subjects to HFNC $(n=169)$ versus oxygen therapy ( $n=171$ ) for the first $2 \mathrm{~d}$ postextubation. The primary outcome was the number of subjects with a $\mathrm{S}_{\mathrm{pO}_{2}} / \mathrm{F}_{\mathrm{IO}_{2}}>445$ after day 2.79 On day 3 , the $\mathrm{S}_{\mathrm{pO}_{2}} / \mathrm{F}_{\mathrm{IO}_{2}}$ was $>445$ in $46.4 \%$ of the subjects on HFNC versus $42.4 \%$ of the subjects on oxygen therapy, $P=.45 .{ }^{79}$ Escalation of respiratory support (use of NIV, CPAP, high-flow face mask, or oxygen therapy after trial discontinuation) occurred in $27.8 \%$ of subjects on HFNC versus $45 \%$ of subjects on oxygen therapy $(P=.001)$, but no long-term outcomes differed. ${ }^{79}$

Stephan et $\mathrm{al}^{80}$ compared the use of HFNC $(n=414)$ versus NIV $(n=416)$ in subjects after cardiac surgery who developed ARF in a noninferiority study conducted in 6 French ICUs. HFNC was not inferior to NIV. Treatment failed in 91 of 416 in the NIV group versus 87 of 414 subjects in the HFNC group. Re-intubation was required in 
57 subjects on NIV versus 58 subjects on HFNC. ${ }^{80}$ Gas exchange and postoperative pulmonary complications were similar in the 2 groups, and no difference in ICU mortality was noted (23 in the NIV group versus 28 in the HFNC group). ${ }^{80}$ Corley et al ${ }^{81}$ evaluated the use of $\operatorname{HFNC}(n=81)$ versus oxygen therapy $(n=74)$ immediately after extubation in subjects who had cardiac surgery and with a body mass index $>30 \mathrm{~kg} / \mathrm{m}^{2}$. No differences in the primary outcome of atelectasis were noted on day 1 or day 5 . There also were no differences in oxygenation or breathing frequency between the groups. ${ }^{81}$

\section{Summary of HFNC in Surgical Subjects}

Analysis of the current data available does not indicate that HFNC is superior to any other postextubation ventilatory support in surgical subjects. However, HFNC is not inferior to any of these techniques. Subject tolerance and comfort is clearly better with HFNC. The HFNC is more comfortable than a tight fitting mask and, as a result, may be a better choice than other approaches. A special comment regarding patients who are obese is indicated; I would not expect an HFNC to have any marked effect on atelectasis in this population because of the low level of PEEP established with an HFNC. ${ }^{25-28}$ When considering the level of PEEP needed in these patients during mechanical ventilation ${ }^{73,74}$ and the fact that many have sleep apnea that requires nocturnal CPAP well over $10 \mathrm{~cm} \mathrm{H}_{2} \mathrm{O}$, therapy that provides a consistent and high CPAP level is indicated, not HFNC. ${ }^{82,83}$

\section{HFNC Postextubation in General ICU Populations}

Rittayamai et al ${ }^{84}$ randomized subjects after extubation from a general ICU population to 2 protocols: HFNC for $30 \mathrm{~min}$ followed by a non-rebreathing mask for $30 \mathrm{~min}$ $(n=9)$, and a non-rebreathing mask for $30 \mathrm{~min}$ followed by HFNC for $30 \mathrm{~min}(n=8)$. HFNC resulted in less dyspnea $(P=.04)$ and a lower breathing frequency $(P=.009)$ and heart rate $(P=.006)$; however, no outcome variables were evaluated. ${ }^{84} \mathrm{~A}$ higher percent of subjects preferred the HFNC to the high-flow face mask ( $88 \%$ to $12 \%){ }^{84}$ Maggiore et al ${ }^{85}$ randomized subjects to HFNC $(n=53)$ versus an air-entrainment mask $(n=52)$ immediately after extubation. After $24 \mathrm{~h}$, the estimated $\mathrm{P}_{\mathrm{aO}_{2}} / \mathrm{F}_{\mathrm{IO}_{2}}$ values were higher with $\mathrm{HFNC}(287 \pm 74 \mathrm{~mm} \mathrm{Hg}$ versus $247 \pm 81 \mathrm{~mm} \mathrm{Hg}, P=.03) .{ }^{85}$ Interface displacement (32\% versus $56 \%, P=.001$ ), oxygen desaturations $(40 \%$ versus $70 \%, P<.001$ ), and reintubations ( $4 \%$ versus $21 \%$, $P=.01)$ as well as any form of additional ventilatory support $(7 \%$ versus $35 \%, P<.001)$ were all less frequent with HFNC. ${ }^{85}$ Discomfort was greater in the air-entrainment mask group. ${ }^{85}$ Brotfain et al ${ }^{86}$ retrospectively reviewed 67 subjects after after extubation in a 1-y period. The subjects were grouped into those who received HFNC $(n=34)$ versus a non-rebreathing mask $(n=33){ }^{86}$ The use of HFNC resulted in improved $\mathrm{P}_{\mathrm{aO}_{2}} / \mathrm{F}_{\mathrm{IO}_{2}}$ after extubation, $P<.05$, and there were more ventilator-free days in the HFNC group (mean $\pm \mathrm{SD}, 4.14 \pm 2.2 \mathrm{~d}$ versus $3.0 \pm 2.0 \mathrm{~d}, P=.03)$, and fewer subjects who required intubation ( 1 versus $6, P=.04$ ); here were no differences in ICU LOS or mortality. ${ }^{86}$ Table 8.

Hernandez et al ${ }^{87,88}$ evaluated the impact of HFNC immediately after extubation in 2 separate groups of subjects, those at high risk for re-intubation ${ }^{87}$ and those at low risk of re-intubation. ${ }^{88}$ The variables used to separate the subjects into low versus high risk are outlined in Table 9. Essentially, all the subjects extubated in the 3 participating ICUs were allocated into 1 of the 2 groups. In the high-risk group, the subjects were randomly allocated to receive HFNC $(n=290)$ versus NIV $(n=314)$ for $24 \mathrm{~h}$ immediately after extubation. ${ }^{87} \mathrm{Re}$-intubation was not required in 66 subjects in the HFNC group and 60 subjects in the NIV group, with no significant difference. ${ }^{87}$ Postextubation respiratory failure was experienced in 76 subjects in the HFNC group and 125 subjects in the NIV group (95\% CI [Confidence interval] 12.9, 6.6 to $\infty) .{ }^{87}$ Postextubation LOS was less in the HFNC group (3 [interquartile range, 1-7] d versus 4 [interquartile range, 2-9] $\mathrm{d}, P=.048) .{ }^{87}$ Other outcomes were similar, including mortality. Adverse events that required withdrawal of therapy were noted in $42.9 \%$ of the subjects in the NIV group and $0 \%$ of the subjects in the HFNC group, $P=.001 .{ }^{87}$ In the second study by Hernández et al, ${ }^{88}$ subjects at low risk of re-intubation were randomized to HFNC $(n=264)$ versus standard oxygen therapy $(n=263)$. Re-intubation within $72 \mathrm{~h}$ was more common in the standard oxygen therapy group $(12.2 \%$ versus $4.9 \%, P=.004)$, as was postextubation respiratory failure (14.4\% versus $8.3 \%, P=.03) .88$ ICU and hospital LOS, mortality, and adverse events were similar between the 2 groups.

The final RCT in this category was by Fernandez et al. ${ }^{89}$ The investigators randomized subjects immediately after extubation who were at high risk for re-intubation to either HFNC or to standard oxygen therapy. The study was stopped early because of low recruitment, with 78 subjects randomized to HFNC and 77 to standard oxygen therapy. Postextubation respiratory failure developed in $20 \%$ of subjects who received HFNC versus $27 \%$ who received standard oxygen therapy, $P=.2 .{ }^{89} \mathrm{Re}$-intubation occurred in 9 subjects in the HFNC group versus 12 subjects in the standard oxygen therapy group, $P=.5$; no differences were found in ICU or hospital LOS or in mortality. ${ }^{89}$

\section{Summary of HFNC in Postextubation Subjects in General ICU}

There is no question that the use of HFNC immediately after extubation in patients at high risk of re-intubation is 


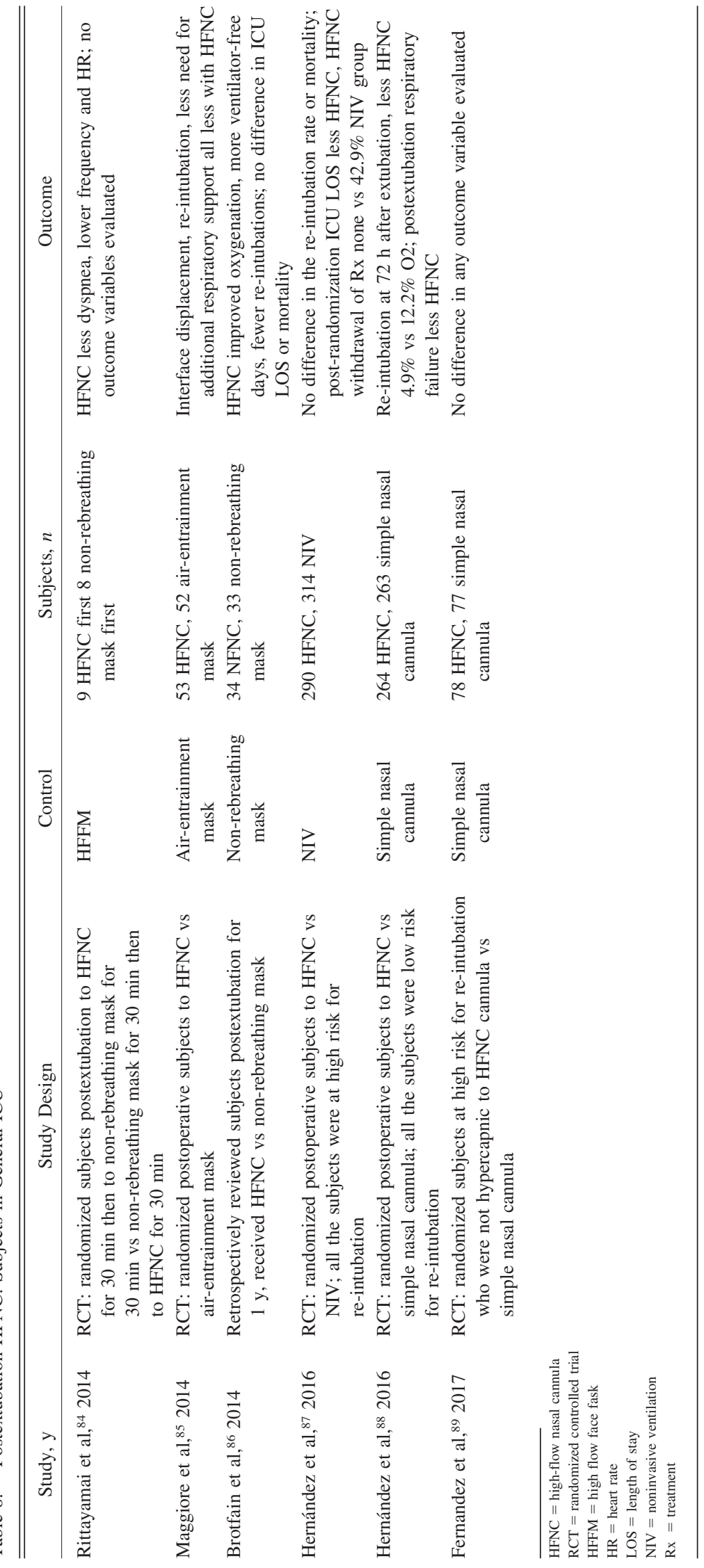


beneficial. HFNC reduces the rate of ARF development, re-intubation, and ICU LOS. However, the routine use of HFNC in patients at low risk must be questioned. Based on the 2 studies by Hernández et al, ${ }^{87,88}$ every patient extubated in the ICU would require HFNC, which is clear if Table 9 is examined. All the subjects were divided into either low risk or high risk for re-intubation, and the reintubation rate in the Hernández et al ${ }^{88}$ low-risk standard oxygen therapy group was very high (12.2\%), much higher than would be expected in a low-risk group of patients in a general ICU. Patients identified as low risk for re-intubation in most ICUs have a very low rate, typically $<5 \%$, while only receiving standard oxygen therapy.

\section{Summary}

A recent meta-analysis by $\mathrm{Ni}$ et $\mathrm{al}^{90}$ of the use of HFNC after extubation determined that HFNC is superior to standard oxygen therapy in preventing re-intubation but not

Table 9. Criteria Used to Separate Subjects Into High Risk and Low Risk for Re-Intubation

\begin{tabular}{lll}
\hline \hline \multicolumn{1}{c}{$\begin{array}{c}\text { Mechanical Ventilation for } \\
\text { at Least } 12 \mathrm{~h} \text { and at } \\
\text { Least One of the Following }\end{array}$} & Low Risk & High Risk \\
\hline $\begin{array}{l}\text { Age } 65 \mathrm{y} \\
\text { APACHE II score of }\end{array}$ & $\leq$ & $>$ \\
12 at extubation & $\leq$ & $>$ \\
BMI $30 \mathrm{~kg} / \mathrm{m}_{2}$ & No problem & Problem \\
Pulmonary Secretions & $\leq 1$ & $>1$ \\
Comorbidities & No & Yes \\
HF cause for mechanical ventilation & No & Yes \\
Moderate-severe COPD & No problem & Problem \\
Airway patency & $\leq 7 \mathrm{~d}$ & $>7 \mathrm{~d}$ \\
Duration of mechanical venitlation & & \\
& & \\
Based on References 87 and 88. & & \\
APACHE $=$ Acute Physiology and Chronic Health Evaluation & \\
BMI = body mass index & & \\
HF = heart failure & & \\
\hline
\end{tabular}

superior to NIV. They also determined that HFNC was no better than either standard oxygen therapy or NIV in reducing mortality or LOS in the ICU..$^{90}$ Unfortunately, their analysis did not stratify subjects by risk for re-intubation. Helviz and Einav, ${ }^{4}$ in a recent review of HFNC in adults, indicated that HFNC reduces re-intubation and mortality as much as NIV postextubation in subjects at high risk. But HFNC has not been shown to be beneficial in abdominal surgery subjects and its use in patients at low risk after extubation is controversial. In a recent editorial regarding the use of HFNC postextubation, Mauri et al ${ }^{91}$ indicate that HFNC should be limited to patients at risk for reintubation. Similar results are found in systematic reviews $^{3,55}$ and meta-analysis ${ }^{15}$ of the use of NIV and CPAP postextubation. The data are positive in supporting the use of these therapies in the management of patients at high risk of postextubation failure but not for those at low risk of re-intubation. The European Respiratory Society/American Thoracic Society clinical practice guidelines ${ }^{56}$ recommends the use of NIV and/or CPAP for patients with postoperative ARF. No guidelines recommend the use of any of these therapies in patients at low risk of re-intubation.

As outlined in Table 10, currently, there are insufficient data to support the use of NIV, CPAP, or HFNC in the management of patients at low risk of needing re-intubation. However, there is universal support for the use of NIV, CPAP, or HFNC for patients at high risk of requiring re-intubation or patients who develop ARF after extubation. The specific circumstances in which each therapy should be used is unclear.

HFNC has the distinct advantage over NIV and CPAP of being more comfortable and least likely to fail because of patient tolerance, but it should not be the choice of therapy when specific and high levels of PEEP are required or when ventilation is needed. CPAP and HFNC have been advocated for the treatment of hypoxemic respiratory failure; however, if the failure is a result of atelectasis, then CPAP is again the therapy of choice because PEEP is indicated and can be applied at a percise level. This is most likely the reason why HFNC has not

Table 10. Postextubation Recommendations for the Use of HFNC, NIV, and CPAP

\begin{tabular}{ll}
\hline \hline \multicolumn{1}{c}{ Parameter } & \multicolumn{1}{c}{ Recommendation } \\
\hline $\begin{array}{l}\text { Patients at low risk for re-intubation } \\
\text { Patients at high risk for re-intubation }\end{array}$ & No indication for HFNC, NIV or CPAP \\
Patients who need ventilatory assistance & NIV indicated \\
Patients who require high and precise CPAP levels because of hypoxemic respiratory \\
$\quad$ failure (obese, abdominal surgery, significant atelectasis) \\
Patients with hypoxemic respiratory failure who do not require high or precise CPAP levels & CPAP indicated \\
HFNC = high-flow nasal cannula & HFNC indicated \\
NIV = noninvasive ventilation & \\
\hline
\end{tabular}




\section{Noninvasive Support in PosteXtubation Respiratory Failure}

proved to be beneficial in subjects with upper-abdominal surgery or subjects who are obese when high levels of CPAP are required to stabilize the lung. Patients who are hypercarbic require ventilation, hence NIV is indicated. In patients with hypoxemia who require either CPAP or HFNC, the choice is dependent on the need for precise and high PEEP levels. If precise and high PEEP is not needed, then HFNC is the choice.

All 3 therapies have a failure rate that requires intubation. The most difficult task of the bedside clinician is determining when the therapy has failed and when to intubate. As dramatically shown by Esteban et al, ${ }^{40}$ delaying intubation in patients who are not responding positively to any of these therapies leads to increased mortality, most likely caused by the induction of lung injury by vigorous ventilatory efforts. ${ }^{43,44} \mathrm{We}$ should always error on the conservative side, and any patient who does not respond to therapy within 1 to $2 \mathrm{~h}$ should be intubated. Specifically, patients whose clinical status has not improved, demonstrated by the continual presence of tachypnea, tachycardia, hypotension, or hypertension, and the use of accessory muscles of ventilation in spite of a normalization of blood gases, should be intubated.

\section{REFERENCES}

1. Krinsley JS, Reddy PK, Iqbal A. What is the optimal rate of failed extubation? Crit Care 2012;16(1):111.

2. Kulkarni AP, Agarwal V. Extubation failure in intensive care unit: predictors and management. Indian J Crit Care Med 2008;12(1):1-9.

3. Chiumello D, Chevallard G, Gregoretti C. Non-invasive ventilation in postoperative patients: a systematic review. Intensive Care Med 2011;37(6):918-929.

4. Helviz Y, Einav S. A systematic review of the high-flow nasal cannula for adult patients. Crit Care 2018;22(1):71-82.

5. O'Donohue WJ Jr. Postoperative pulmonary complications. When are preventive and therapeutic measures necessary? Postgrad Med 1992;91(3):167-170, 173-175.

6. Smetana GW. Preoperative pulmonary evaluation. N Engl J Med 1999;340(12):937-944.

7. Chawla G, Drummond GB. Fentanyl decreases end-expiratory lung volume in patients anaesthetized with sevoflurane. $\mathrm{Br} \mathrm{J}$ Anaesth 2008;100(3):411-414.

8. Hedenstierna G, Edmark L. The effects of anesthesia and muscle paralysis on the respiratory system. Intensive Care Med 2005;31(10): 1327-1335.

9. Esteban A, Frutos-Vivar F, Ferguson ND, Arabi Y, Apezteguía C, González M, et al. Noninvasive positive-pressure ventilation for respiratory failure after extubation. N Engl J Med 2004;350(24):24522460.

10. Ferrer M, Esquinas A. Arancibia F, Bauer TT, Gonzalez G, Carrillo A, et al. Noninvasive ventilation during persistent weaning failure: a randomized controlled trial. Am J Respir Crit Care Med 2003;168(1): 70-76.

11. Ferreyra G, Squadrone V, Ranieri VM. In Vincent JL: Acute respiratory failure after abdominal surgery. In: Year of intensive care and emergency medicine. Berlin: Springer; 2005:10-18.

12. Harpole DH Jr, DeCamp MM Jr, Daley J, Hur K, Oprian CA, Henderson WG, Khuri SF. Prognostic models of thirty-day mortality and morbidity after major pulmonary resection. J Thorac Cardiovasc Surg 1999;117(5):969-979.

13. Dureuil B, Cantineau JP, Desmonts JM. Effects of upper or lower abdominal surgery on diaphragmatic function. Br J Anaesth 1987; 59(10):1230-1235.

14. Simonneau G, Vivien A, Sartene R, Kunstlinger F, Samii K, Noviant Y, Duroux P. Diaphragm dysfunction induced by upper abdominal surgery, role of postoperative pain. Am Rev Respir Dis 1983;128(5): 899-903.

15. Mehta S, Hill NS. Noninvasive ventilation. Am J Respir Crit Care Med 2001;163(2):540-577.

16. de Waal CG, Hutten GJ, Kraaijenga JV, de Jongh FH, van Kaam AH. Electrical activity of the diaphragm during nCPAP and high flow nasal cannula. Arch Dis Child Fetal Neonatal Ed 2017;102(5): F434-F438.

17. Ritchie JE, Williams AB, Gerard C, Hockey H. Evaluation of a humidified nasal high-flow oxygen system, using oxygraphy, capnography and measurement of upper airway pressures. Anaesth Intensive Care 2011;39(6):1103-1110.

18. Wettstein RB, Shelledy DC, Peters JI. Delivered oxygen concentrations using low-flow and high-flow nasal cannulas. Respir Care 2005; 50(5):604-609.

19. Corley A, Caruana LR, Barnett AG, Tronstad O, Fraser JF. Oxygen delivery through high-flow nasal cannulae increase end-expiratory lung volume and reduce breathing frequency in post-cardiac surgical patients. Br J Anaesth 2011;107(6):998-1004.

20. Roca O, Riera J, Torres F, Masclans JR. High-flow oxygen therapy in acute respiratory failure. Respir Care 2010;55(4):408-413.

21. Nishimura M. High-flow nasal cannula oxygen therapy in adults: physiological benefits, indication, clinical benefits, and adverse effects. Respir Care 2016;61(4):529-541.

22. Jiang Y, Liang Y, Kacmarek RM. The principle of upper airway unidirectional flow facilitates breathing in humans. J Appl Physiol 2008;105(3):854-858.

23. Mauri T, Turrini C, Eronia N, Grasselli G, Volta GA, Bellani G, Pesenti A. Physiologic effects of high-flow nasal cannula in acute hypoxemic respiratory failure. Am J Respir Crit Care Med 2017; 159(9):1207-1215.

24. Parke R, McGuinness S, Eccleston M. Nasal high-flow therapy delivers low level positive airway pressure. Br J Anaesth 2009;103(6): 886-890.

25. Groves N, Tobin A. High flow nasal oxygen generates positive airway pressure in adult volunteers. Aust Crit Care 2007;20(4):126131.

26. Riera J, Pérez P, Cortés J, Roca O, Masclans JR, Rello J. Effect of high-flow nasal cannula and body position on end-expiratory lung volume: a cohort study using electrical impedance tomography. Respir Care 2013;58(4):589-596.

27. Parke RL, Bloch A, McGuinness SP. Effect of very-high-flow nasal therapy on airway pressure and end-expiratory lung impedance in healthy volunteers. Respir Care 2015;60(10):1397-1403.

28. Nava S, Ambrosino N, Clini E, Prato M, Orlando G, Vitacca M, et al. Noninvasive mechanical ventilation in the weaning pf patients with respiratory failure due to chronic obstructive pulmonary disease. A randomized, controlled study. Ann Intern Med 1998;128(9): 721-728.

29. Girault C, Daudenthun I, Chevron V, Tamion F, Leroy J, Bonmarchand $\mathrm{G}$. Noninvasive ventilation as a systematic extubation and weaning technique in acute-on-chronic respiratory failure. A prospective, randomized controlled study. Am J Respir Crit Care Med 1999; 160(1):86-92.

30. Trevisan CE, Vieira SR, Research Group in Mechanical Ventilation Weaning. Non-invasive mechanical ventilation may be useful in treat- 


\section{Noninvasive Support in PosteXtubation Respiratory Failure}

ing patients who fail weaning from invasive mechanical ventilation: a randomized clinical trial. Critical Care 2008;12(2):R51-R60.

31. Girault C, Bubenheim M, Abroug F, Diehl JL, Elatrous S, Beuret P, et al.; VENISE Trial Group. Non-invasive ventilation and weaning in patients with chronic hypercapnic respiratory failure. Am J Respir Crit Care Med 2011;184(6):672-679.

32. Nava S, Gregoretti C, Fanfulla F, Squadrone E, Grassi M, Carlucci A, et al. Noninvasive ventilation to prevent respiratory failure after extubation in high-risk patients. Crit Care Med 2005;33(11):24652470.

33. Ferrer M, Valencia M, Nicolas JM, Bernadich O, Badia JR, Torres A. Early noninvasive ventilation averts extubation failure in patients at risk. A randomized trial. Am J Respir Crit Care Med 2006;173(2): 164-170.

34. Ferrer M, Sellarés J, Valencia M, Carrillo A, Gonzalez G, Badia JR, et al. Non-invasive ventilation after extubation in hypercapnic patients with chronic respiratory disorders: randomized controlled trial. Lancet 2009;374(9695):1082-1088.

35. Khilnani GC, Galle AD, Hadda V, Sharma SK. Non- invasive ventilation after extubation in patients with chronic obstructive airways disease: a randomized controlled trial. Anesth Intensive Care 2011; 39(2):217-223.

36. Schmidt GA, Girard TD, Kress JP, Morris PE, Ouellette DR, Alhazzani W, et al.; ATS/CHEST Ad Hoc Committee on Liberation from Mechanical Ventilation in Adults. Offical Executive Summary of an American Thoracic Society/American College of Chest Physicians Clinical Practice Guideline: Liberation from Mechanical Ventilation. Am J Respir Crit Care Med 2017;195(1):115-119.

37. Torres A, Gatell JM, Aznar E, el-Ebiary M, Puig de la Bellacasa J, González J, et al. Re-intubation increases the risk of nosocomial pneumonia in patients needing mechanical ventilation. Am J Respir Crit Care Med 1995;152(1):137-141.

38. Esteban A, Anzueto A, Frutos F, Alía I, Brochard L, Stewart T, et al.; Mechanical Ventilation International Study Group. Characteristics and outcomes in adults receiving mechanical ventilation: a 28 day international study. JAMA 2002;287(3):345-355.

39. Keenan SP, Powers C, McCormack DG, Block G. Noninvasive positive-pressure ventilation for postextubation respiratory distress. A randomized controlled trial. JAMA 2002;287(24):3238-3244.

40. Esteban A, Frutos-Vivar F, Ferguson ND, Arabi Y, Apezteguía C, González M, et al. Noninvasive positive-pressure ventilation for respiratory failure after extubation. N Engl J Med 2004;350(24):24522460.

41. Li HL, Chen L, Brochard L. Protecting lungs during spontaneous breathing: what can we do? J Thorac Dis 2017;9(9):2777-2781.

42. Pham T, Telias I, Piraino T, Yoshida T, Brochard LJ. Asynchrony consequences and management. Crit Care Clin 2018;34(3):325-341.

43. Yoshida T, Uchiyama A, Matsuura N, Mashimo T, Fujino Y. The comparison of spontaneous breathing and muscle paralysis in two different severities of experimental lung injury. Crit Care Med 2013; 41(2):536-545.

44. Yoshida T, Nakahashi S, Nakamura MAM, Koyama Y, Roldan R, Torsani V, et al. Volume-controlled ventilation does not prevent injurious inhalation during spontaneous effort. Am J Respir Crit Care Med 2017;196(5):590-601.

45. Curtis JR, Cook DJ, Sinuff T, White DB, Hill N, Keenan S, et al.; Society of Critical Care Medicine Palliative Noninvasive Positive Ventilation Task Force. Non-invasive positive pressure ventilation in critical and palliative care settings: understanding the goals of therapy. Crit Care Med 2007;35(3):932-939.

46. Aguiló R, Togores B, Pons S, Rubí M, Barbé F, Agustí AG. Noninvasive ventilator support after lung resectional surgery. Chest 1997; 112(1):117-121.
47. Joris JL, Sottiaux TM, Chiche JD, Desaive CJ, Lamy ML. Effect of bi-level positive airway pressure (BiPAP) nasal ventilation on the postoperative pulmonary restrictive syndrome in obese patients undergoing gastroplasty. Chest 1997;111(3):665-670.

48. Antonelli M, Conti G, Bufi M, Costa MG, Lappa A, Rocco M, et al. Noninvasive ventilation for treatment of acute respiratory failure in patients undergoing solid organ transplantation. A randomized trial. JAMA 2000;283(2):235-241.

49. Auriant I, Jallot A, Hervé P, Cerrina J, Le Roy Ladurie F, Fournier $\mathrm{J}$, et al. Noninvasive ventilation reduces mortality in acute respiratory failure following lung resection. Am J Respir Crit Care Med 2001;164(7):1231-1235.

50. Rocco M, Conti G, Antonelli M, Bufi M, Costa MG, Alampi D, et. al. Non-invasive pressure support ventilation in patients with acute respiratory failure after bilateral lung transplantation. Intensive Care Med 2001;27(10):1622-1626.

51. Ebeo CT, Benotti PN, Byrd RP Jr, Elmaghraby Z, Lui J. The effect of bi-level positive airway pressure on postoperative pulmonary function following gastric surgery for obesity. Respir Med 2002;96(9): 672-676.

52. Perrin C, Jullien V, VénissacN, Berthier F, Padovani B, Guillot F, et. al. Prophylactic use of noninvasive ventilation in patients undergoing lung resectional surgery. Respir Med 2007;101(7):1572-1278.

53. Michelet P, D'Journo XB, Seinaye F, Forel JM, Papazian L, Thomas $P$. Non-invasive ventilation for treatment of postoperative respiratory failure after oesophagectomy. Br J Surg 2009;96(1):54-60.

54. Jaber S, Lescot T, Futier E, Paugam-Burtz C, Seguin P, Ferrandiere M, et al.; NIVAS Study Group. Effect of noninvasive ventilation on tracheal re-intubation among patients with hypoxemic respiratory failure following abdominal surgery: a randomized trial. JAMA 2016; 315(13):1345-1353.

55. Jaber S, De Jong A, Castagnoli A, Futier E, Chanques G. Noninvasive ventilation after surgery. Ann Fr Anesth Reanim 2014;33(78) $487-491$.

56. Rochwerg B, Brochard L, Elliott MW, Hess D, Hill N, Nava S, et al.; Raoof S Members of the Task Force. Offical ERS/ATS clinical practice guidelines: noninvasive ventilation for acute respiratory failure. Eur Respir J 2017;50(2). pii: 1602426.

57. Pinilla JC, Oleniuk FH, Tan L, Rebeyka I, Tanna N, Wilkinson A, Bharadwaj B. Use of a nasal continuous positive airway pressure mask in the treatment of postoperative atelectasis in aortocoronary bypass surgery. Crit Care Med 1990;18(8):836-840.

58. Thomas AN, Ryan JP, Doran BR, Pollard BJ. Nasal CPAP after coronary artery surgery. Anaesthesia 1992;47(4):316-319.

59. Jousela I, Räsänen J, Verkkala K, Lamminen A, Mäkeläinen A, Nikki P. Continuous positive airway pressure by mask in patients after coronary surgery. Acta Anaesthesiol Scand 1994;38(4):311316.

60. Pasquina P, Merlani P, Granier JM, Ricou B. Continuous positive airway pressure versus noninvasive pressure support ventilation to treat atelectasis after cardiac surgery. Anesth Analg 2004;99(4):10011008 , table of contents.

61. Zarbock A, Mueller E, Netzer S, Gabriel A, Feindt P, KindgenMilles D. Prophylactic nasal continuous positive airway pressure following cardiac surgery protects from postoperative pulmonary complications. Chest 2009;135(5):1252-1259.

62. Carlsson C, Sondén B, Thylén U. Can postoperative continuous positive airway pressure (CPAP) prevent pulmonary complications after abdominal surgery? Intensive Care Med 1981;7(5):225-229.

63. Ricksten SE, Bengtsson A, Soderberg C, Thorden M, Kvist H. Effects of periodic positive airway pressure by mask on postoperative pulmonary function. Chest 1986;89(6):774-781. 
64. Lindner KH, Lotz P, Ahnefeld FW. Continuous positive airway pressure effect on functional residual capacity, vital capacity and its subdivisions. Chest 1987;92(1):66-70.

65. Denehy L, Carroll S. A randomized controlled trial comparing periodic mask CPAP with physiotherapy after abdominal surgery. Physiother Res Int 2001;6(4):236-250.

66. Fagevik Olsén M, Wennberg E, Johnsson E, Josefson K, Lönroth H, Lundell L. Randomized clinical study of the prevention of pulmonary complications after thoracoabdominal resection by two different breathing techniques. Br J Surg 2002;89(10):1228-1234.

67. Squadrone V, Coha M, Cerutti E, Schellino MM, Biolino P, Occella P, et al.; Piedmont Intensive Care Units Network (PICUN). Continuous positive airway pressure for treatment of postoperative hypoxemia. A randomized controlled trial. JAMA 2005;293(5):589-595.

68. Kindgen-Milles D, Müller E, Buhl R, Böhner H, Ritter D, Sandmann W, Tarnow J. Nasal-continuous positive airway pressure reduces pulmonary morbidity and length of hospital stay following thoracoabdominal aortic surgery. Chest 2005;128(2):821-828.

69. Stock MC, Downs JB, Gauer PK, Alster JM, Imrey PB. Prevention of postoperative pulmonary complications with CPAP, incentive spirometry, and conservative therapy. Chest 1985;87(2):151-157.

70. Böhner H, Kindgen-Milles D, Grust A, Buhl R, Lillotte WC, Müller BT, et al. Prophylactic nasal continuous positive airway pressure after major vascular surgery: results of a prospective randomized trial. Langenbecks Arch Surg 2002;387(1):21-26.

71. Neligan PJ, Malhotra G, Fraser M, Williams N, Greenblatt EP, Cereda M, Ochroch EA. Continuous positive airway pressure via the Boussignac System immediately after extubation improves lung function in morbidly obese patients with obstructive sleep apnea undergoing laparoscopic bariatric surgery. Anesthesiology 2009;110(4):878-884.

72. Gaszynski T, Tokarz A, Piotrowski D, Machala W. Boussignac CPAP in the postoperative period in morbidly obese patients. Obes Surg 2007; 17(4):452-456.

73. Pirrone M, Fisher D, Chipman D, Imber DA, Corona J, Mietto C, et al. Recruitment maneuvers and positive end-expiratory pressure titration in morbidly obese ICU patients. Crit Care Med 2016;44(2):300-307.

74. Fumagalli J, Berra L, Zhang C, Pirrone M, Santiago RRS, Gomes S, et al. Transpulmonary pressure describes lung morphology during decremental positive end-expiratory pressure trials in obesity. Crit Care Med 2017;45(8):1374-1381.

75. Dhillon NK, Smith EJT, Ko A, Harada MY, Polevoi D, Liang R, et al. Extubation to high-flow nasal cannula in critically ill surgical patients. J Surg Res 2017;217:258-264.

76. Tiruvoipati R, Lewis D, Haji K, Botha J. High-flow nasal oxygen vs high-flow face mask: a randomized crossover trial in extubated patients. J Crit Care 2010;25(3):463-468.

77. Tu G, He H, Yin K, Ju M, Zheng Y, Zhu D, Luo Z. High-flow nasal cannula versus noninvasive ventilation for treatment of acute hypoxemic respiratory failure in renal transplant recipients. Transplant Proc 2017;49(6):1325-1330.

78. Futier E, Paugam-Burtz C, Godet T, Khoy-Ear L, Rozencwajg S, Delay JM, et al.; OPERA study investigators. Effect of early post- extubation high-flow nasal cannula vs conventional oxygen therapy on hypoxaemia in patients after major abdominal surgery: a French multicenter randomized controlled trial (OPERA). Intensive Care Med 2016;42(12):1888-1898.

79. Parke R, McGuinness S, Dixon R, Jull A. Open-label, phase II study of routine high-flow nasal oxygen therapy in cardiac surgical patients. Br J Anaesth 2013;111(6):925-931.

80. Stéphan F, Barrucand B, Petit P, Rézaiguia-Delclaux S, Médard A, Delannoy B, et al.; BiPOP Study Group. High-flow nasal oxygen vs noninvasive positive airway pressure in hypoxemic patients after cardiothoracic surgery. A randomized clinical trial. JAMA 2015; 313(23):2331-2339.

81. Corley A, Bull T, Spooner AJ, Barnett AG, Fraser JF. Direct extubation onto high-flow nasal cannulae post-cardiac surgery versus standard treatment in patients with a BMI $\geq 30$ : a randomized controlled trial. Intensive Care Med 2015;41(5):887-894.

82. Chirinos JA, Gurubhagavatula I, Teff K, Rader DJ, Wadden TA, Townsend R, et al. CPAP, weight loss or both for sleep apnea. N Engl J Med 2014;370(24):2265-2275.

83. Joosten SA, Hamilton GS, Naughton MT. Impact of weight loss management in OSA. Chest 2017;152(1):194-203.

84. Rittayamai N, Tscheikuna J, Rujiwit P. High-flow nasal cannula versus conventional oxygen therapy after endotracheal extubation: A randomized crossover physiologic study. Respir Care 2014;59(4): 485-490.

85. Maggiore SM, Idone FA, Vaschetto R, Festa R, Cataldo A, Antonicelli $\mathrm{F}$, et al. Nasal high-flow versus venture mask oxygen therapy after extubation. Effect on oxygenation, comfort, and clinical outcome. Am J Respir Crit Care Med 2014;190(3):282-288.

86. Brotfain E, Zlotnik A, Schwartz A, Frenkel A, Koyfman L, Gruenbaum SE, Klein M. Comparison of the effectiveness of high flow nasal oxygen cannula vs. standard non-rebreather oxygen face mask in post-extubation intensive care unit patients. Isr Med Assoc J 2014; 16(11):718-722.

87. Hernández G, Vaquero C, Colinas L, Cuena R, González P, Canabal A, et al. Effect of postextubation high-flow nasal cannula vs noninvasive ventilation on re-intubation and postextubation respiratory failure in high-risk patients. A randomized clinical trial. JAMA 2016; 316(15):1565-1574.

88. Hernández G, Vaquero C, González P, Subira C, Frutos-Vivar F, Rialp G, et al. Effect of postextubation high-flow nasal cannula vs conventional oxygen therapy on re-intubation in low-risk patients. A randomized clinical trial. JAMA 2016;315(13):1354-1361.

89. Fernandez R, Subira C, Frutos-Vivar F, Rialp G, Laborda C, Masclans JR, et al. High-flow nasal cannula to prevent postextubation respiratory failure in high-risk non-hypercapnic patients: a randomized multicenter trial. Ann Intensive Care 2017;7(1):47.

90. Ni YN, Luo J, Yu D, Liang BM, Yao R, Liang SA. Can high-flow nasal cannula reduce the rate of re-intubation in adult patients after extubation? A meta -analysis. BMC Pulm Med 2017;17(1):142.

91. Mauri T, Grasselli G, Jaber S. Respiratory support after extubation: noninvasive ventilation or high-flow nasal cannula, as appropriate. Ann Intensive Care 2017;7(1):52.

\section{Discussion}

* Hess: I think that one category of patients (and patients who are obese fall into this group) who get into trouble after extubation are patients who have unrecognized sleep-disordered breathing. Maybe what we're really treating with NIV is their undiagnosed obstructive sleep apnea.

Kacmarek: I agree. If you look at the history of these patients, you'll find that many of them get extubated and nobody realizes (because they haven't carefully read the history) that they do have sleep apnea or other forms of sleep disorders that would necessitate some type of therapy after extubation, whether they're obese or lean.

* Hess: Right, so we might want to consider adding to the list of people 
who are at risk, in addition to history of pulmonary disease and congestive heart failure, is a patient who may have obstructive sleep apnea.

Kacmarek: In the studies that have been done that has not been included as criteria and I extracted right from the criteria of the studies, but I agree with you $100 \%$.

* Hess: That's my point. I don't think it was considered.

Kacmarek: It's just like the obese population, very few subjects in any randomized controlled trial are obese. I presented that one study ${ }^{1}$ early on with HFNC in subjects after cardiac surgery and with a body mass index $>30 \mathrm{~kg} / \mathrm{m}^{2}$, but that's the unusual study, it's hard to find studies that look at the obese population.

Hill: Bob [Kacmarek], you've done a very nice job of summarizing what is a very complicated collection of articles in the literature. One of the big challenges, of course, is that we have so many different ways of using noninvasive techniques in the postextubation period; we're using it prophylactically in patients at low risk, or at high risk, or after they've developed frank respiratory failure. We can use it earlier or later, and, in different patient populations, depending on the cause of respiratory compromise. This problem is compounded in the postoperative setting in which your pie chart showed many different types of surgery but very few studies relevant to a single type. Yet, we try to generalize about the whole category of postoperative use. It really does make it difficult to analyze. One of the studies I wanted to comment on specifically was the low-risk study by Hernández et al. ${ }^{2}$

\footnotetext{
* Dean R Hess PhD RRT FAARC, Managing Editor, RESPIRATORY CARE.
}

The intubation rate they observed in their control group was $12 \%$, which is hardly a low-risk group in my view, and many of the subjects were postoperative or had neurologic problems. Is that correct?

\section{Kacmarek: Correct.}

Hill: I think it gets at the issue of what kinds of patients you include in your study population. If you have people with potential swallowing or secretion problems, as the subjects in the study by Hernández et $\mathrm{al}^{2}$ probably had, then HFNC may be helpful. However, a more typical lowrisk postextubation population probably wouldn't manifest a difference in intubation rate because the control rate would likely be considerably lower than in the Hernández's study.

Kacmarek: Right, if you go to your standard surgical ICU and you use the 2 categories low risk and high risk, that's everybody. In our ICU, that is, every patient we extubate would need to go on HFNC, and I clearly don't believe that's the case. I think we need better studies. On the high-risk side, I don't think any of us would question the need for some type of noninvasive support, but, on the low-risk side, I don't think we've teased out the correct subgroups who would benefit from HFNC.

Hill: The study by Ferrer et $\mathrm{al}^{3}$ on subjects who were hypercapnic, the thing that disturbed me about that study was that the main difference they showed was in the rate of respiratory failure, which they defined as exceeding a certain level of hypercapnia. So you randomize them to go on NIV or standard oxygen, and it makes sense that NIV would prevent greater hypercapnia, thus preventing respiratory failure as they defined it. Also, based on what we know now about the overuse of $\mathrm{O}_{2}$ in patients with COPD and who are hypercapnic, you could create a situation in which just by virtue of the aggressiveness of your oxygenation ...

Kacmarek: You create a problem. Yeah, I agree, this was not the best study. To me, this was a little confusing because I didn't think the criteria for fitting the ARF definition was as clear as it could have been.

Hill: Even though I agree with the conclusion that NIV is helpful when people are hypercapnic and are at risk of going into respiratory failure, I'm not sure this was the best way to demonstrate it.

Volsko: With regard to the neonatal data that you presented for HFNC, what was the approach the investigators took with setting the flow? In early use of HFNC in practice, there was some hesitancy to use the higher flows because the CPAP level was thought to be highly variable. $^{4}$

Kacmarek: If you look at the top group in which they looked at failure, ${ }^{5}$ the first study included was from 2011. So there was only one older study that they included in the criteria when selecting the particular studies included in the meta-analysis. I agree, the flows early on were all over the place and nothing was standardized, but I think the majority of the studies are recent enough that they reflect standard care in our neonatal ICU.

\section{REFERENCES}

1. Corley A, Bull T, Spooner AJ, Barnett AG, Fraser JF. Direct extubation onto high-flow cannulae post-cardiac surgery versus standard treatment in patients with a BMI $>30$ : a randomized controlled trial. Intensive Care Med 2015;41(5):887-894.

2. Hernández G, Vaquero C, González P, Subira C, Frutos-Vivar F, Rialp G, et al. Effect of postextubation high-flow nasal cannula vs conventional oxygen therapy on reintubation in low-risk patients: a randomized clinical trial. JAMA 2016;315(13):1354-1361. 
3. Ferrer M, Sellarés J, Valencia M, Carrillo A, Gonzalez G, Badia JR, et al. Non-invasive ventilation after extubation in hypercapnic patients with chronic respiratory disorders: randomized controlled trial. Lancet 2009; 374(9695):1082-1088.
4. Kubicka ZJ, Limauro J, Darnall RA. Heated, humidified high-flow nasal cannula therapy: yet another way to deliver continuous positive airway pressure? Pediatrics 2008;121(1):82-88.

5. Conte F, Orfeo L, Gizzi C, Massenzi L,
Fasola S. Rapid systematic review shows that using a high-flow nasal cannula is inferior to nasal continuous positive airway pressure as a first-line support in preterm neonates. Acta Paediatr 2018;107(10):1684-1696.

This article is approved for Continuing Respiratory Care Education credit. For information and to obtain your CRCE

(free to AARC members) visit 